Part of Journal of Research of the National Bureau of Standards, Volume 35, July 1945

\title{
THERMODYNAMIC PROPERTIES OF 1,3-BUTADIENE IN THE SOLID, LIQUID, AND VAPOR STATES
}

\section{By Russell B. Scott, Cyril H. Meyers, Robert D. Rands, Jr., Ferdinand G. Brickwedde, and Norman Bekkedahl}

This paper presents a detailed description of apparatus used and the results obtained in the following measurements relating to the thermodynamic properties of 1,3-butadiene in the solid, liquid, and vapor states: (1) Specific heats from $-258^{\circ}$ to $+30^{\circ} \mathrm{C}$, (2) heat of fusion, (3) heats of vaporization from $-26^{\circ}$ to $+23^{\circ} \mathrm{C}$, (4) vapor pressures from $-78^{\circ}$ to $+110^{\circ} \mathrm{C}$, (5) liquid densities from $-78^{\circ}$ to $+95^{\circ} \mathrm{C}$, (6) vapor densities from $30^{\circ}$ to $150^{\circ} \mathrm{C}$, and (7) the critical pressure, volume, and temperature of 1,3-butadiene. Tables embodying the results of these measurements are included for specific heats, enthalpy, and entropy of the solid, liquid, and vapor.

\section{CONTENTS}

I. Introduction

II. Preparation of samples_...

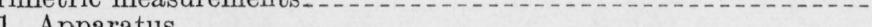

(a) Calorimeter

(b) Electric control circuits _........ 47

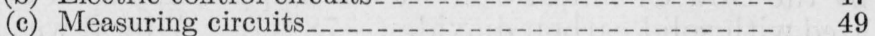

2. Specific heat

(a) Method of measurement_........ 51

(b) Method of calculation

(c) Results

3. Heat of fusion

(a) Method of measurement

(b) Results

4. Heat of vaporization

(a) Method of measurement

(b) Results _...

5. Accuracy of calorimetric measurements

IV. Pressure-volume-temperature measurements_............. 58

1. Vapor pressure

(a) Measurements from $195^{\circ}$ to $288^{\circ} \mathrm{K} \ldots$

(b) Measurements from $0^{\circ}$ to $152^{\circ} \mathrm{C} \ldots$

(c) Vapor-pressure equation $\ldots$

(d) Comparison with data of other observers

2. Density of superheated vapor.

(a) Method and apparatus... 65

(b) Results of measurements and their formulation.... 66

3. Density of saturated liquid........ 68

(a) Method and apparatus 68

(b) Results of measurements and their formulation.... 69

(c) Comparison with other data..... 71

4. Rate of polymerization

5. Critical constants_...... 72 
V. Purity of samples and melting point of pure butadiene

VI. Derived properties and formulated tables of the thermodynamic prop-

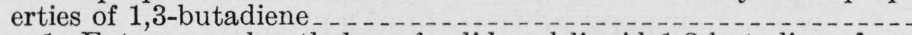

1. Entropy and enthalpy of solid and liquid 1,3-butadiene from

2. Thermodynamic properties of liquid and vapor 1,3 -butadiene from $-109^{\circ}$ to $+150^{\circ} \mathrm{C}$

\section{INTRODUCTION}

The measurements of the thermodynamic properties of 1,3-butadiene described in this paper were undertaken in response to requests for data needed in the Government's synthetic-rubber program. Most of the experimental data were made available previously to the synthetic-rubber industry in the form of reports $[1,2]^{1}$ submitted to the Office of the Rubber Director and in a National Bureau of Standards Letter Circular [3]. As these reports were rather brief, more detailed descriptions of the apparatus, methods, and results are given here.

Empirical equations were constructed to represent the experimental results and used to calculate a thermodynamically consistent set of tables of various derived properties, including enthalpy and entropy of 1,3-butadiene in the solid, liquid, and vapor state. In these calculations use was made of measurements of the specific heat of 1,3-butadiene vapor previously published [4] and an equation of state for the vapor that represents measurements over a wide range of temperature and pressure.

\section{PREPARATION OF SAMPLES}

The butadiene from which the samples were prepared was furnished by the Dow Chemical Co. It was shipped in a steel cylinder refrigerated with solid carbon dioxide $\left(-78^{\circ} \mathrm{C}\right)$. After it was received it was kept at or near $-78^{\circ} \mathrm{C}$, except while being transferred from one container to another. The butadiene was removed from the cylinder by evaporating it into one-half-liter Pyrex flasks at $-78^{\circ} \mathrm{C}$. These were provided with seals that could later be broken with magnetic plungers so that all the handling of the material could be carried out in the absence of air. The supply of butadiene, somewhat less than 2 liters, was stored in four such flasks.

It appeared that a small amount of carbon dioxide had leaked into the cylinder during transit while it was in a $\mathrm{CO}_{2}$ atmosphere at such a low temperature that the pressure inside the cylinder was less than atmospheric. The carbon dioxide impurity was noticed during the transfer as it caused blocking by not condensing with the butadiene. It did condense readily in a liquid-air trap, which fact led to the belief that it was carbon dioxide and not air. The blocking occurred tbree times during the filling of the first half-liter flask. When it occurred, the flask and cylinder were connected through a stopcock to a vacuum system and pumped for a few seconds. In this way most of the carbon dioxide was removed, together with some butadiene. No difficulty was experienced during the filling of the three other half-liter flasks. These flasks are designated by the numbers $1,2,3$, and 4 in the order of their filling.

1 Figures in brackets indicate the literature references at the end of this paper. 
During the course of the experiments four samples were prepared. Sample 1 was prepared by evaporating the $450-\mathrm{ml}$ contents of flask 3 at about $-30^{\circ} \mathrm{C}$, separating a middle fraction of about $110 \mathrm{ml}$. This fraction was frozen with liquid air with the intention of pumping off any air that may have been present. However, a pressure measurement, made with a McLeod gage, showed this pumping to be unnecessary. The butadiene seemed to be free of any impurity that had an appreciable vapor pressure at the temperature of liquid air. After melting the butadiene, another evaporation was carried out, and the middle $95 \mathrm{ml}$ was collected. This constituted sample 1 . The unused material from both evaporations was returned to the half-liter flask.

The material from which sample 2 was prepared consisted of about $100 \mathrm{ml}$ of butadiene also taken from flask 3 . The distillate was separated into five fractions. Fraction 1, about $10 \mathrm{ml}$ of liquid, was discarded. Fraction 2 was a very small amount, about $0.2 \mathrm{ml}$ of liquid. Fraction 3 was the main body of the material, about $80 \mathrm{ml}$ of liquid, which constituted sample 2. Fraction 4 was another small sample about the same size as fraction 2. Fraction 5, about $10 \mathrm{ml}$ of liquid, was discarded.

The vapor pressures of fractions 2 and 4 were compared at a pressure of about $1 \mathrm{~atm}$ by means of a differential vapor-pressure apparatus similar to that described by Shepherd [5]. No difference in vapor pressures was detected, although a difference of $0.05 \mathrm{~mm} \mathrm{Hg}$ could have been noticed. This equality of vapor pressures indicated that further distillation of fraction 3 would have little effect.

Sample 2 was prepared by fractional distillation by the use of a still with a rectifying column. This apparatus is shown in figure 1. The boiling reservoir, $A$, is surmounted by a rectifying column, $B$, consisting of a monel tube with a deep helical groove. The Pyrex container surrounding the rectifying column fits so closely that, during operation, the liquid sealed the space between the glass and the metal, causing all the vapor and most of the refluxing liquid to traverse the helical groove, a path of about $6 \mathrm{~m}$. The evacuated space between the two walls of the Pyrex container insulated the boiler and rectifying column. The heat required for the boiling is supplied by the heater, $C$, consisting of $34 \mathrm{ohms}$ of fiber-glass-insulated constantan wire wound on the stem of the copper piece, $D$. The inverted mushroom of copper conducts the heat from the constantan heater to the bottom of the boiling reservoir. The walls of the condenser, $E$, are in contact with the stirred alcohol bath in which the still is immersed. The bath is refrigerated by means of a copper coil into which high-pressure carbon dioxide expands. An electric heater is provided so that excess refrigeration can be compensated and a constant bath temperature maintained. During the operation of the still the temperature of the bath was kept at about $-25^{\circ} \mathrm{C}$ and manually controlled so as not to vary more than 0.05 degree. The butadiene vapor was withdrawn at $F$. The withdrawal rate and the boiling rate were adjusted so that the reflux ratio was about 15 .

Sample 3 was prepared by fractional crystallization of material from flask 2. The apparatus used is shown in figure 2. The butadiene in flask $A$ was partially frozen by cooling produced by the liquid air surrounding tube $C$. The air space separating flask $A$ and tube $C$ provided enough insulation to prevent too rapid freezing. About 20 minutes were required to freeze $150 \mathrm{ml}$ of butadiene. While the 
freezing proceeded, the magnetic stirrer, $D$, kept the liquid agitated so that there would not be a concentration of impurity at the surface of the solid as it formed. Two fractional crystallizations were performed. After the first, about $50 \mathrm{ml}$ remained liquid and was poured into flask $B$. The remaining solid was melted and again fractionally crystallized, this time discarding into flask $B$ about $75 \mathrm{ml}$ of unfrozen

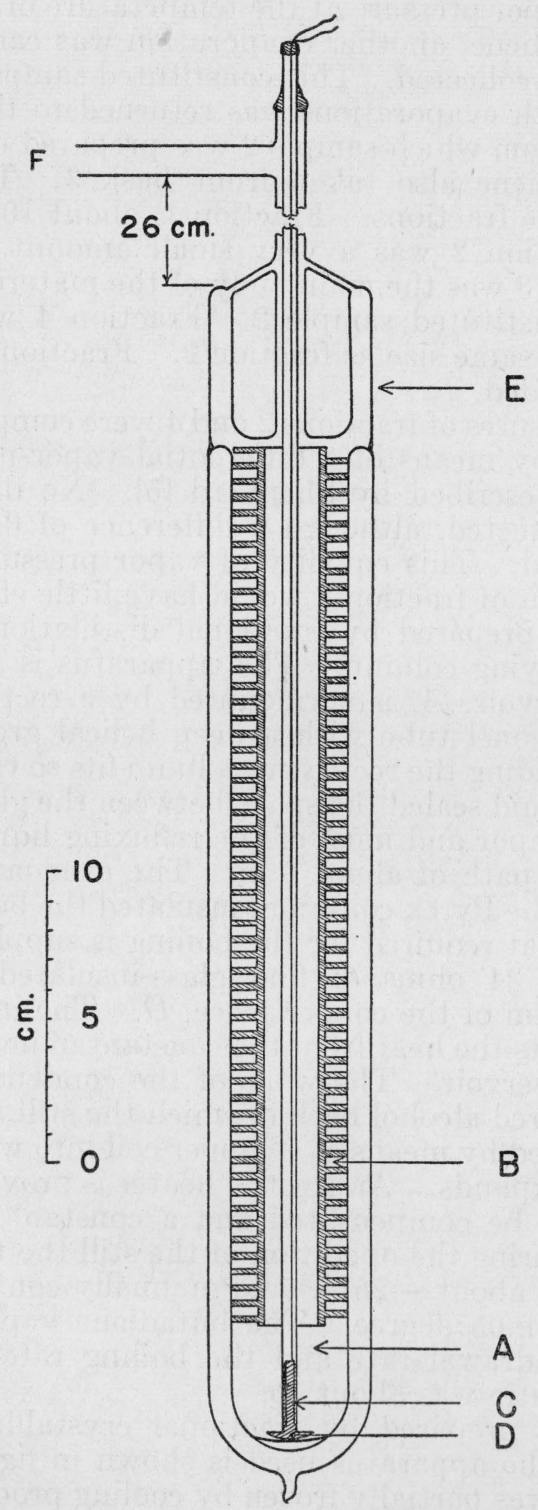

Figure 1.-Still with rectifying column used to purify butadiene.

$A$, boiling reservoir; $B$, rectifying column; $C$, heater; $D$, copper conductor; $E$, condenser; $F$, withdrawal line. 
material. Flask $B$ was then sealed off, and the $125 \mathrm{ml}$ of butadiene remaining in flask $A$ constituted sample 3.

Sample 4 was prepared by passing the butadiene, from flask 4 , as a vapor over freshly outgassed silica gel. After condensing, the buta-

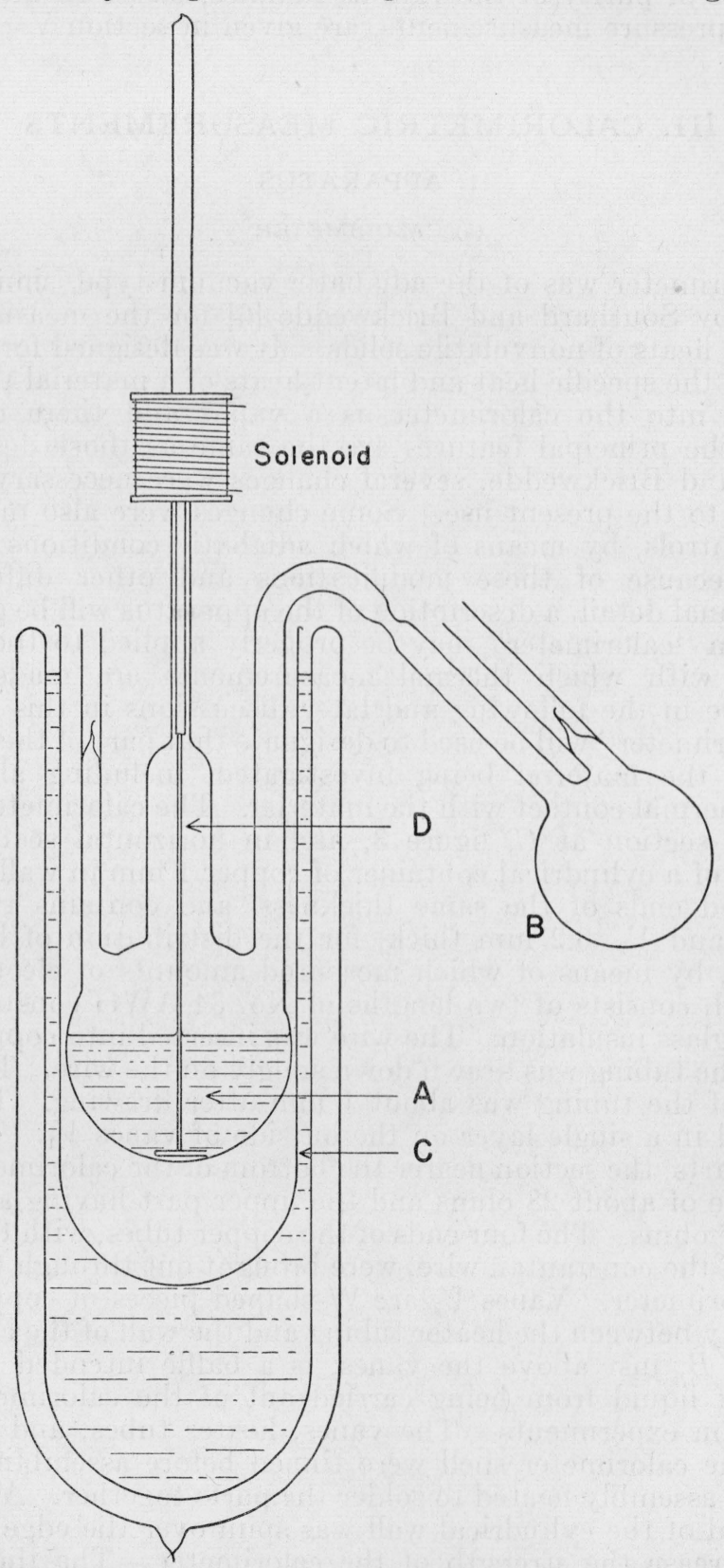

Figure 2.-Fractional cystallization apparatus used to purify butadiene.

$A$, butadiene in freezing flask; $B$, waste flask; $C$, tube providing air space around freezing flask; $D$, stirrer. 
diene was fractionally crystallized three times, and finally the recrystallized material was distilled twice. In this process only about $60 \mathrm{ml}$ of butadiene was obtained from an initial supply of $400 \mathrm{ml}$.

Estimates of purity of the various samples, based on melting data and vapor-pressure measurements, are given in section $\mathrm{V}$.

\section{CALORIMETRIC MEASUREMENTS}

\section{APPARATUS}

(a) CALORIMETER

The calorimeter was of the adiabatic vacuum type, similar to one described by Southard and Brickwedde [6] for the measurement of the specific heats of nonvolatile solids. It was designed for the measurement of the specific heat and latent heats of a material that can be introduced into the calorimeter as a vapor and there condensed. Although the principal features are the same as those described by Southard and Brickwedde, several changes were necessary to adapt the design to the present use. Some changes were also made in the electric controls, by means of which adiabatic conditions are maintained. Because of these modifications and other differences in constructional detail, a description of the apparatus will be given here.

The term "calorimeter" may be properly applied to the complete apparatus with which thermal measurements are made, but for convenience in the following and later discussions in this paper, the word "calorimeter" will be used to designate that part of the apparatus containing the material being investigated, including all parts in intimate thermal contact with the material. The calorimeter is shown in vertical section at $C$, figure 3 , and in horizontal section at $C^{\prime}$. It consists of a cylindrical container of copper $1 \mathrm{~mm}$ in wall thickness, with domed ends of the same thickness, and contains two sets of vanes, $V_{1}$ and $V_{2}, 0.2 \mathrm{~mm}$ thick, for the distribution of heat. The heater, $H_{1}$, by means of which measured amounts of electric energy were added, consists of two lengths of No. $34 \mathrm{AWG}$ constantan wire with fiber-glass insulation. The wire was inserted into copper tubing, and then the tubing was drawn down snugly on the wire. The outside diameter of the tubing was about $1 \mathrm{~mm}$ after drawing. The tubing was wound in a single layer on the outside of vanes $V_{1}$. The heater is in two parts, the section nearer the bottom of the calorimeter having a resistance of about $28 \mathrm{ohms}$ and the upper part having a resistance of about $37 \mathrm{ohms}$. The four ends of the copper tubes, with the projecting ends of the constantan wire, were brought out through the bottom of the calorimeter. Vanes $V_{2}$ are $\mathrm{W}$-shaped pieces of copper formed to fit closely between the heater tubing and the wall of the calorimeter. The cone, $B$, just above the vanes, is a baffle intended to prevent droplets of liquid from being carried out of the calorimeter during vaporization experiments. The vanes, heater tubes, and inside surfaces of the calorimeter shell were tinned before assembling and the completed assembly heated to solder the parts together. About $2 \mathrm{~mm}$ of each end of the cylindrical wall was spun over the edge of the end cap to increase the strength of the calorimeter. The thermometer, $T$, used to determine the temperature of the calorimeter is a fourlead, strain-free, platinum resistance thermometer in a platinum 
tube. This type of thermometer has been described by Southard and Milner [7]. The calibration of the thermometer used in this investigation has been described by Hoge and Brickwedde [8]. The thermometer contains helium and is sealed at the bottom by a soft glass cap, through which the platinum leads pass. Intimate thermal contact

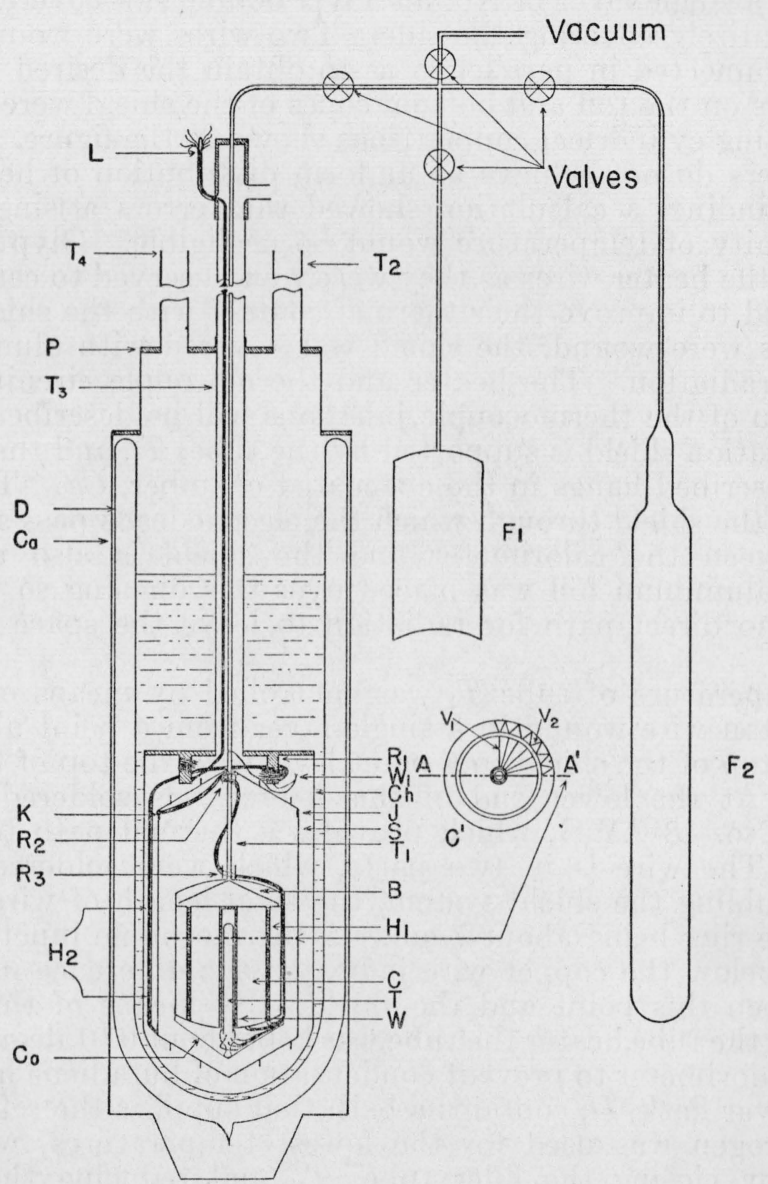

FIGURE 3.-Sectional view of calorimeter and auxiliary apparatus.

$L$, electrical leads; $P$, top plate of hydrogen container; $T_{3}$ monel tube for evacuation; $D$, Dewar flask; $C a$, brass case; $K$, point at which leads pass through shield; $R_{2}$ and $R_{3}$, copper rings; $H_{2}$, cable heater; $C 0$, aluminum cone; $T_{2}$, monel tube for exhausting over bath; $R_{1}$, brass ring; $W_{1}$, wire for thermal shunt; $C h$, vacuum chamber; $J$ sliding joint between top and side of shield; $S$, shield; $T_{1}$, filling tube; $B$, baffle; $H_{1}$, heater; $C$, calorimeter; $T$, resistance thermometer; $W$, thermometer well; $F_{1}$, weighing flask; $F_{2}$ reservoir; $V_{1}$ and $V_{2}$, copper vanes.

between the thermometer and the well, $W$, was attained by filling the excess space around the thermometer with low-melting $\left(90^{\circ} \mathrm{C}\right)$ solder. The cone, $C_{0}$, is a piece of aluminum foil 0.001 in. thick to trap heat radiated from the exposed ends of the heaters. The calorimeter is supported by the monel tube, $T_{1}$, through which the calorimeter was filled and emptied.

The radiation shield, $S$, is made of sheet copper $0.4 \mathrm{~mm}$ thick. It is cylindrical with conical ends. The bottom is soldered to the 
cylindrical side, and the joint, $J$, at the top is a close sliding fit between the side and a flange on the top. Electric heaters on the shield and differential thermocouples between the calorimeter and shield were provided so that all parts of the shield could be kept at the temperature of the calorimeter. The heater on the side of the shield consists of a single layer of No. 30 AWG double silk-covered constantan wire entirely covering the side. Two wires were wound side by side and connected in parallel so as to obtain the desired resistance. The heaters on the top and bottom cones of the shield were wound on the projecting cylindrical copper rings shown in the figure. Although these heaters do not achieve as uniform distribution of heat as does the side winding, a calculation showed that errors arising from the nonuniformity of temperature would be negligible. Glyptal lacquer applied to the heater wires as they were wound served to cement them in place and to improve their thermal contact with the shield. After the heaters were wound, the shield was covered with aluminum foil to reduce radiation. The heater and thermocouple circuits and the distribution of the thermocouple junctions will be described later.

The radiation shield is supported by the tube, $T_{1}$, and the assembly thus far described hangs in the evacuated chamber, $\mathrm{Ch}$. There is an opening in the shield through which the electric leads pass so that the space between the calorimeter and the shield is also evacuated. However, aluminum foil was placed over this opening so that there would be no direct path for radiation to leave the space inside the shield.

The temperature of tube $T_{1}$ was controlled by means of a heater of constantan wire wound in a single layer from a point about $2 \mathrm{~cm}$ above the top of the shield to a point level with the top of the Dewar flask, $D$. At the lower end of this heater was soldered a copper wire, $W_{1}$, No. 18 AWG, which provides a thermal path to the cold ring, $R_{1}$. The wire is in two parts, which were soldered together after assembling the shield system, the total length of wire from the tube to the ring being about $7 \mathrm{~cm}$. A thermocouple junction on the tube just below the copper wire indicated the difference in temperature between this point and the shield. By means of this thermocouple and the tube heater the tube was kept about 0.01 degree warmer than the calorimeter to prevent condensation of butadiene in the tube.

The Dewar flask, $D$, contains a bath that supplies the refrigeration. Solid hydrogen was used for the lowest temperatures, which were obtained by closing the filler tube, $T_{4}$, and reducing the pressure over a bath of liquid hydrogen by pumping out the vapor through the tube, $T_{2}$, by means of a large vacuum pump. For successively higher temperatures the refrigerating materials were liquid hydrogen, liquid air, solid carbon dioxide, ice, and water. When liquid or solid hydrogen was used as the refrigerant, the brass case, $C a$, surrounding the Dewar flask was immersed in liquid air, in a larger flask, to a level above the top plate, $P$.

The electric leads enter the vacuum space through the wax seal at $L$ and pass down through the tube, $T_{3}$. They are brought to the temperature of the bath by being wound twice around the brass ring, $R_{1}$, and are cemented to it with Glyptal lacquer. Leaving the ring, the leads pass down outside the shield and are brought to the temperature of the shield by means of the heater, $\mathrm{H}_{2}$, wound on the leads. This preheating of the leads before they come into contact 
with the shield is done to avoid a cold spot on the shield. The leads are then wound in a single layer as a helix passing up the side of the shield under the shield heater and making four turns around the shield. At point $K$ some of the leads are separated from the bundle and are connected to the heaters and thermocouples. The remaining leads enter the shield and make a turn around ring $R_{2}$, which is soldered to the top of the shield. They then pass to the calorimeter, making a turn around ring $R_{3}$, which is soldered to the top of the calorimeter. The leads are cemented to the rings with Glyptal lacquer and are bound down tightly with thread. Leaving ring $R_{3}$ the leads pass down the side of the calorimeter and are connected to the thermometer and heater. All the leads are No. 34 AWG copper wire insulated with enamel and silk.

The filling tube, $T_{1}$, communicates through the valves with the flasks, $F_{1}$ and $F_{2}$, or with the vacuum system. The amount of butadiene involved in an experiment was determined by transferring the butadiene from the calorimeter to the brass container, $F_{1}$, and weighing $F_{1}$ before and after the transfer. A union not shown permitted the removal of $F_{1}$ so that it could be weighed on an analytical balance. In the Pyrex flask, $F_{2}$, the approximate volume of the butadiene was visually estimated before transferring it to the calorimeter. This flask was also used as an auxiliary reservoir in experiments on the heat of vaporization.

\section{(b) ELECTRIC CONTROL CIRCUITS}

The thermocouple circuits and the locations of the junctions on the apparatus are shown in figure 4 . The numbered arrows on the diagram of the calorimeter and shield show the locations of the junctions and refer also to the corresponding junctions shown in the circuit diagrams, $A$ and $B$. Multiple-junction thermocouples were used between the shield and the calorimeter, as it is here that the most accurate control is necessary. The three-junction couple between the calorimeter and the side and bottom of the shield was wired so that the galvanometer, $G_{2}$, could be connected through the plug contacts, $P$, to any adjacent pair of leads from junctions $1,2,3$, and 4 . This allowed the operator to explore the temperature distribution over the shield so that the ratio of the heat supplied to the side and bottom could be adjusted to minimize the temperature differences. While measurements were being made the contacts, $P$, were connected to leads 1 and 4 , thus using the total emf generated by the three-junction thermocouple. The six-junction thermocouple, between the top of the shield, 8 , and the top of the calorimeter, 9 , permits the detection of very small temperature differences between these two points. Very accurate control was desirable here to prevent heat conduction between the shield and the calorimeter along the leads and the filler tube. The elements of the multiple-junction thermocouples were constantan and Chromel-P. The combination of these alloys has a greater thermoelectric power than constantan-copper, and Chromel-P possesses the additional advantage that its thermal conductivity is much less than that of copper. Copper-constantan junctions at 11 and 12 with the reference junction at 10 were used in maintaining temperature equality between these points. Single junctions were used at 11 and 12 as high accuracy is not necessary in controlling the temperature $649238-45-4$ 
of these points. The constantan and Chromel-P thermocouple wires were No. $32 \mathrm{AWG}$, double silk insulated. All the junctions except 11 and 12 were enclosed in flat sheaths about $3 \mathrm{~mm}$ wide and $8 \mathrm{~mm}$ long, made of sheet copper $0.2 \mathrm{~mm}$ thick. Strips of mica were used to insulate the wires from the copper sheaths. A cross section of this arrangement is shown at $C$, figure 4 . After inserting the junctions and the mica insulating strips into the copper sheath, the copper was crimped tightly on the mica by pressing in a vise. Junction 11 was insulated with silk floss and inserted into the bundle of leads, which were then bound together with thread and impregnated with Glyptal lacquer. Junction 12 was insulated with silk floss and bound to the

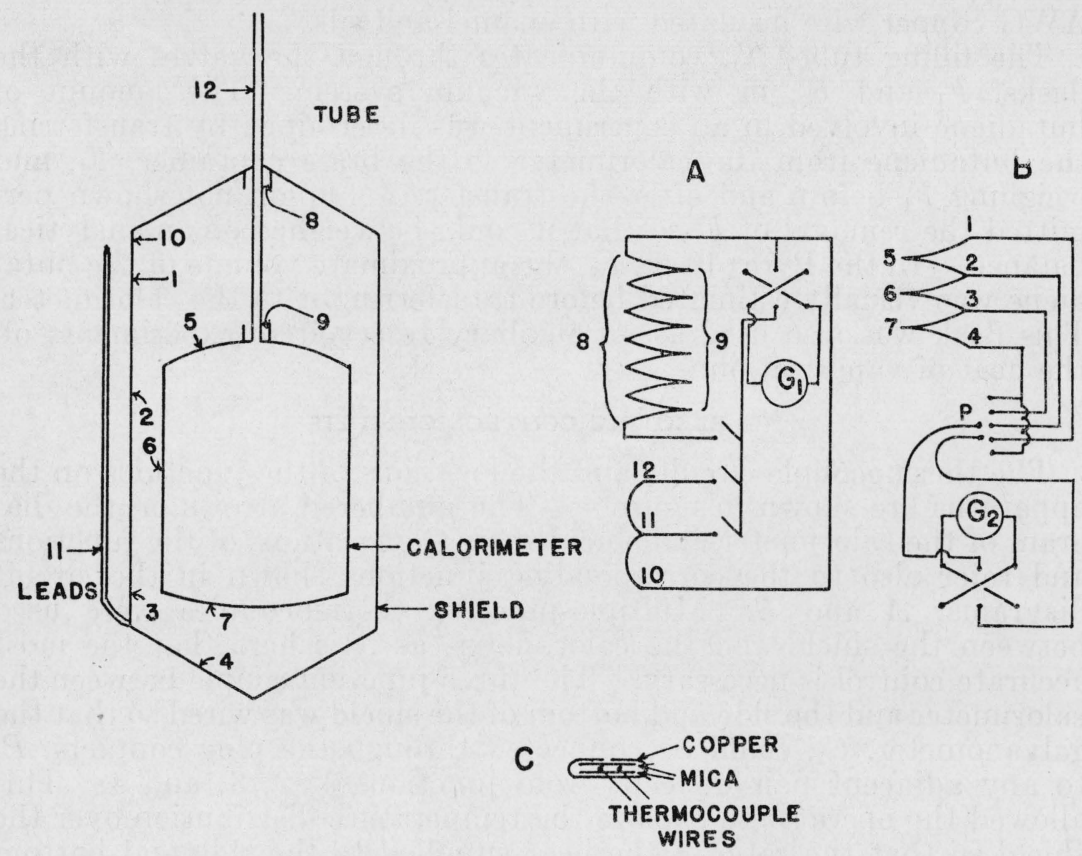

Figure 4.-Diagram of thermocouple circuits showing locations of junctions.

$A$, circuits for top, cable, and tube; $B$, circuits for side and bottom; $C$, enlarged diagram of thermojunction.

tube with thread, Glyptal lacquer again being used as a cement for improving thermal contact. The sheathed junctions were held in place on the surfaces of the calorimeter and shield by wedging them under small bridges of copper which were soldered to the surfaces. The junctions of the six-junction thermocouple were held against the inner surfaces of the rings, $R_{2}$ and $R_{3}$, by short pieces of watch spring coiled inside the rings. The sensitivity of the thermocouple circuits at $90^{\circ} \mathrm{K}$ were as follows: Top (six junction) $1.6 \mathrm{~mm}$ per millidegree; side (three junction) $0.8 \mathrm{~mm}$ per millidegree; ring and tube (single junction) $0.2 \mathrm{~mm}$ per millidegree.

The control circuit for the shield system is shown in figure 5. The resistances marked side, bottom, top, ring, and tube represent the electric heaters on the respective parts of the adiabatic shield system. 
$A_{1}, A_{2}, A_{3}$, and $A_{4}$ are milliameters for measuring the current in each circuit. The currents supplied to the heaters are controlled by the 1 -amp Variac transformers, $V_{1}$ and $V_{2}$, and the 500 -ohm 50 -w potential-divider rheostats, $R_{1}, R_{2}, R_{3}$, and $R_{4}$. When measurements are being made, the Variacs and rheostats are first adjusted so that the thermocouples on the shield system indicate approximately constant adiabatic conditions and then minor variations are compensated by the use of keys $K_{1}$ and $K_{2}$ in each circuit. $K_{1}$ shorts out a resistor of $100 \mathrm{ohms}$, thus momentarily increasing the current in the circuit, and $K_{2}$ opens the circuit momentarily. This operation is more convenient than changing the rheostat settings to compensate small variations in temperature. The $3,200-\mathrm{ohm}$ potential divider is used

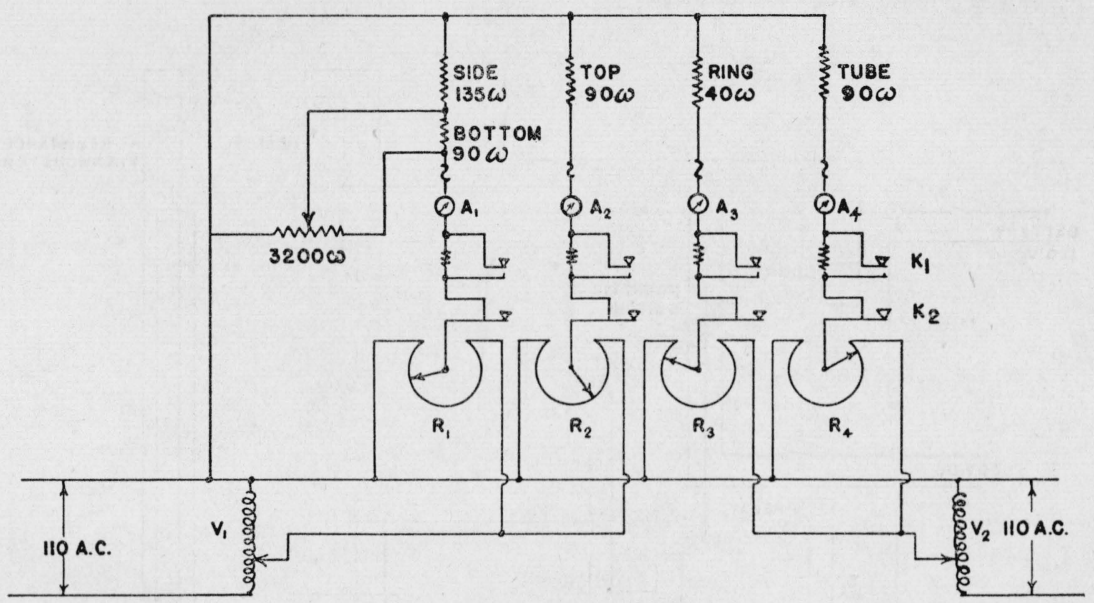

Figure 5.-Diagram of electrical control circuits.

$A_{1}, A_{2}, A_{3}$, and $A_{4}$, ammeters; $K_{1}$ and $K_{2}$, contact keys; $R_{1}, R_{2}, R_{3}$, and $R_{4}$, rheostats; $V_{1}$ and $V_{2}$, Variac transformers.

to adjust the ratio of the heat supplied to the side and bottom parts of the shield. After once adjusting this ratio, it was not found necessary to change it.

\section{(c) MEASURING CIRCUITS}

The circuits for measuring the electric energy supplied to the calorimeter and for measuring its temperature before and after heating are shown in figure 6 . The current through the heater is determined by measuring the potential drop across a 1-ohm standard in series with the heater. The potential across the heater is determined by measuring a part of this potential by means of the volt box, which has a nominal ratio of 1 to 150 . The leads from the volt box to the heater are actually part of the total volt-box resistance, so it is necessary to include their resistance when calculating the potential across the heater. Also part of the current that flows through the 1-ohm standard flows through the volt box; so this correction must be also made in calculating the current through the heater. One of the potential leads is connected to a current lead at its point of thermal 
contact with the shield just before crossing the space between the calorimeter and shield. The other potential lead is connected to the other current lead at its first point of thermal contact with the calorimeter. Thus the measured electric energy is the energy developed in the heater plus the energy developed in that part of one current lead which traverses the space between the shield and the calorimeter. As the two sections of the current leads crossing from the shield to the calorimeter are equivalent, the same amount of heat will be developed in each. If it is assumed that this heat divides equally between the calorimeter and shield, then the heat supplied to the calorimeter will be that which is measured by this arrangement of the potential leads.

The time of heating was controlled and measured by making use of time signals supplied by the Riefler clock in the Time Section of this

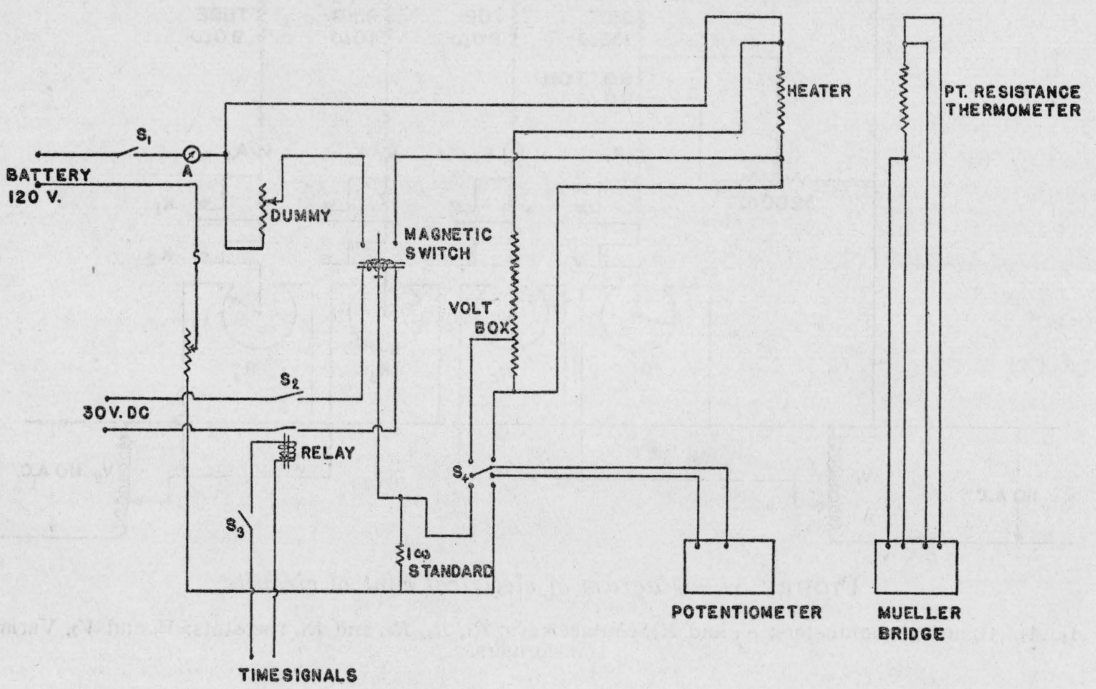

FIgURE 6.-Diagram of measuring circuits.

Bureau. The signals consist of electric impulses at 1-second intervals, except for a 2-second interval at the end of each minute. With switch $S_{3}$ closed, the operator notes the impulses actuating the relay. When the 2-second interval appears, the switch $S_{2}$ is closed, and the next impulse will close the 30-v circuit that actuates the magnetic switch. This switch is so constructed that it may be preset to snap either from left to right or from right to left when it receives the $30-v$ impulse. Thus the time of heating is an integral number of minutes. When the current is not flowing through the calorimeter heater, it flows through a dummy of equal resistance so that the battery current is constant.

Some tests were made in which the magnetic switch was used to operate the clutch of a synchronous interval timer driven by an accurately controlled 60-cycle supply. The reading of the interval timer were found to be within 0.01 second of the interval indicated by the clock-controlled circuit. 
The temperature of the calorimeter was determined by measuring the resistance of the four-lead platinum resistance thermometer by means of the Mueller resistance bridge. The temperature rise during a heat was determined with an accuracy of about 0.001 degree except at temperatures below $20^{\circ} \mathrm{K}$, where the sensitivity was of the order of 0.01 degree.

\section{SPECIFIC HEAT}

\section{(a) METHOD OF MEASUREMENT}

The specific heat of butadiene was obtained from measurements of the heat capacity of the calorimeter and contents. Two sets of heatcapacity measurements were required, one with a large amount of material in the calorimeter and one with a small amount. This procedure, which entails measurements with a small amount of material in the calorimeter rather than with the calorimeter empty, has been described by Osborne [9]. It not only takes into account the tare heat capacity of the calorimeter but makes possible an accurate correction for the effect of the vapor in the space above the solid or liquid in the calorimeter and connecting tube. In making the correction it is not necessary to know the volume of the vapor space nor the temperature of the filler tube, provided the temperature is the same during both sets of measurements.

The data from which heat capacities were calculated consisted of values of the temperature of the calorimeter and contents before and after a measured amount of electric energy had been added. The temperature rise during a heating period was usually about 10 degrees, although it was sometimes as small as 4 degrees or as large as 30 degrees. The rate of temperature rise was varied from about 0.5 degree per minute to 7 degrees per minute. The rate of 7 degrees per minute was taken between $20^{\circ}$ and $30^{\circ} \mathrm{K}$, where the heat capacity was small. This high rate could not safely be reached at temperatures above $100^{\circ} \mathrm{K}$ because the electric leads were too small for the required current. About 3 degrees per minute was the highest rate attained at temperatures above $100^{\circ} \mathrm{K}$. One to two degrees per minute was the normal rate of rise. No consistent differences were observed between the data obtained from long heating intervals and those from short intervals, or between the data obtained from rapid heating and those from slow heating.

\section{(b) METHOD OF CALCULATION}

If a quantity of energy, $\Delta Q$, is required to raise the temperature of the calorimeter and contents an amount, $\Delta T$, the average heat capacity over this temperature interval is $\Delta Q / \Delta T$. The true heat capacity, $d Q / d T$, is the limit of this fraction as $\Delta T$ approaches zero. This limit, $d Q / d T=[G]_{T a}$, may be calculated from the finite measured quantities by means of a relation given by Osborne, Stimson, Sligh, and Cragoe [10].

$$
[G]_{T_{a}}=\left[\frac{d Q}{d T}\right]_{T_{a}}=\frac{\Delta Q}{\Delta T}-\left[\frac{\partial^{2} G}{\partial T^{2}}\right]_{T_{a}} \frac{(\Delta T)^{2}}{24}-\left[\frac{\partial^{4} G}{\partial T^{4}}\right]_{T_{a}} \frac{(\Delta T)^{4}}{1920},
$$

where $\Delta Q$ is the heat added, $\Delta T$ is the temperature rise, and $T_{a}$ is the average temperature of the heating. In making the calculations, the 
derivatives of $G$ with respect to $T$ were replaced by derivatives of $\Delta Q / \Delta T$ with respect to $T$. This is permissible because $\Delta Q / \Delta T$ is approximately equal to $G$. Values of the derivatives were determined from graphs of $\Delta Q / \Delta T$ versus $T$. The last term involving the fourth derivative of $G$ was found to be negligible for all the data for which this method was used. In fact, the term in which the second derivative of $G$ appears was usually less than 0.1 percent of $G$.

The heat-capacity data were correlated and values obtained at intervals of 5 degrees by finding approximate analy tical representations and plotting the deviations of the observed values from these formulas. At low temperatures the heat capacity was represented approximately by a modified Debye function $D[\Theta /(T+B)]$ suggested by Harold $\breve{J}$. Hoge. The Debye function was evaluated from the tables prepared by Beattie [11]. By determining appropriate values of $\Theta$ and $B$, this function could be made to fit the heat-capacity data of the full calorimeter from $15^{\circ}$ to $100^{\circ} \mathrm{K}$. When the calorimeter contained only a small amount of butadiene it was possible to use this function from $15^{\circ}$ to $150^{\circ} \mathrm{K}$, the maximum deviation being about 2.5 percent of the heat capacity at $100^{\circ} \mathrm{K}$. The conventional Debye function $D(\Theta / T)$ could not be used over such large ranges of temperature. At temperatures above $100^{\circ} \mathrm{K}$ for the full calorimeter and above $150^{\circ}$ for the almost empty calorimeter, the heat-capacity data were represented approximately by equations of the form $G=a+b T+c T^{2}$. Tables were constructed giving $G_{b}$, the gross heat capacity when the calorimeter contained a large amount of butadiene, and $G_{a}$, the gross heat capacity when it contained a small amount.

The specific heat along the saturation line, $C_{s a t}$, was calculated by means of the equation

$$
C_{s a t .}=\frac{G_{b}-G_{a}}{M_{b}-M_{a}}+T \frac{d}{d T}\left(v \frac{d P}{d T}\right)
$$

where $v$ is the specific volume of the condensed phase and $P$ is the vapor pressure. This equation was derived from relations given by Osborne [9]. The term $T \frac{d}{d T}\left(v \frac{d P}{d T}\right)$ allows for the fact that the gross heat capacity $G$ includes some heat of vaporization. That is, sufficient butadiene evaporates to maintain saturation pressure in the space above the condensed phase in the calorimeter. The last term of equation 2 is negligible for solid butadiene because the vapor pressure of the solid is low.

Values of $v(d P / d T)$ for the liquid were obtained from vapor-pressure equation 4 (section IV-1, c) and values of $v$ from table 13 .

\section{(c) RESULTS}

The results of the specific-heat determinations are shown in figure 7 and in tables 1 and 2 . The symbol $C_{\text {sat }}$. is used to denote the specific heat at saturation. The graph at the bottom of figure 7 shows the differences between the specific-heat values obtained for the different 
samples in the temperature range $60^{\circ}$ to $215^{\circ} \mathrm{K}$. In the liquid range there is excellent agreement, the differences usually being less than 0.1 percent. However, in the solid state the differences between the specific heats of the different samples is considerably larger. At $70^{\circ} \mathrm{K}$ the specific heat of sample 1 is about 1.8 percent larger than that of sample 4 . It is unlikely that this difference can be accounted for by experimental error as different measurements on the same sample agreed within about 0.1 percent, and in the liquid state the agreement between the measurements on different samples was equally good. It was thought at first that the discrepancies might

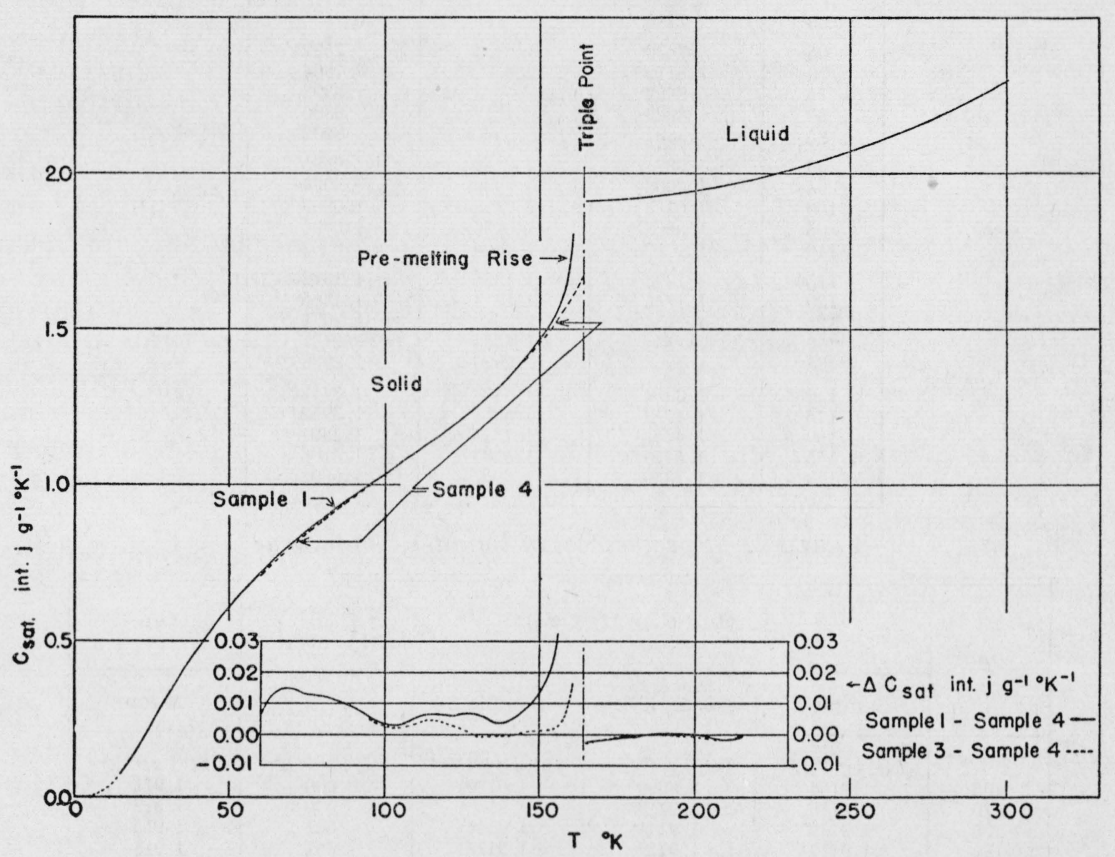

FIGURE 7.-Specific heat along the saturation line for 1,3-butadiene as a function of temperature

have resulted from different rates of cooling of the different samples, but a test made to detect such an effect gave a negative result. The most reasonable conclusion is that the differences were caused by different amounts of impurity in the different samples. This explanation requires that the impurity affect the specific heat to a much greater extent than would be expected from the additive law of specific heats. The large differences just below the triple point are caused by the premelting of samples 1 and 3 . Sample 4 , the specific heat of which is used as the reference in the deviation graph, contained so little impurity that there was no apparent premelting until the temperature was within 0.2 degree of the triple point. 

Journal of Research of the National Bureau of Standards

TABLE 1.-Specific heat of solid 1,3-butadiene

\begin{tabular}{|c|c|c|c|}
\hline \multirow{2}{*}{$T$} & \multicolumn{3}{|c|}{$C_{s a t .}$} \\
\hline & Sample 1 & Sample 3 & Sample 4 \\
\hline $\begin{array}{r}K \\
15 \\
20 \\
25 \\
30 \\
35\end{array}$ & $\begin{array}{c}\text { Int. } j g^{-1}{ }^{\circ} K^{-1} \\
0.07477 \\
.1492 \\
.2341 \\
.3193 \\
.4012\end{array}$ & Int. $j g^{-1}{ }^{\circ} K^{-1}$ & $\begin{array}{c}\text { Int. } j g^{-1}{ }^{\circ} K^{-1} \\
\end{array}$ \\
\hline $\begin{array}{l}40 \\
45 \\
50 \\
55 \\
60\end{array}$ & $\begin{array}{l}.4762 \\
.5447 \\
.6081 \\
.6654 \\
.7186\end{array}$ & - & 0.7136 \\
\hline $\begin{array}{l}65 \\
70 \\
75 \\
80 \\
85\end{array}$ & $\begin{array}{l}.7670 \\
.8112 \\
.8522 \\
.8923 \\
.9307\end{array}$ & - & $\begin{array}{l}.7532 \\
.7964 \\
.8393 \\
.8800 \\
.9202\end{array}$ \\
\hline $\begin{array}{r}90 \\
95 \\
100 \\
105 \\
110\end{array}$ & $\begin{array}{l}.9674 \\
1.0006 \\
1.0333 \\
1.0668 \\
1.1017\end{array}$ & $\begin{array}{l}0.9999 \\
1.0328 \\
1.0656 \\
1.1000\end{array}$ & $\begin{array}{r}.9585 \\
.9954 \\
1.0302 \\
1.0636 \\
1.0963\end{array}$ \\
\hline $\begin{array}{l}115 \\
120 \\
125 \\
130 \\
135\end{array}$ & $\begin{array}{l}\text { 1. } 1376 \\
1.1745 \\
1.2136 \\
1.2524 \\
1.2963 \text {. }\end{array}$ & $\begin{array}{l}\text { 1. } 1358 \\
1.1718 \\
1.2089 \\
\text { 1. } 2474 \\
1.2920\end{array}$ & $\begin{array}{l}\text { 1. } 1312 \\
\text { 1. } 1685 \\
\text { 1. } 2071 \\
1.2481 \\
1.2926\end{array}$ \\
\hline $\begin{array}{l}1403 \\
145 \\
150 \\
155 \\
160\end{array}$ & $\begin{array}{l}1.3454 \mathrm{Z} / \mathrm{L} \\
1.4019 \\
1.4651 \\
1.5450 \\
1.7356\end{array}$ & $\begin{array}{l}\text { 1. } 3408 \mathrm{Z2} \\
1.3951 \\
1.4533 \\
1.5200 \\
1.6097\end{array}$ & $\begin{array}{l}\text { 1. } 3412 \\
\text { 1. } 3942 \\
\text { 1. } 4521 \\
1.5186 \\
1.5968\end{array}$ \\
\hline
\end{tabular}

TABLE 2.-Specific heat of liquid 1,3-butadiene

\begin{tabular}{|c|c|c|c|c|c|}
\hline \multirow{2}{*}{$T$} & \multicolumn{3}{|c|}{$\left(G_{b}-G_{a}\right) /\left(M_{b}-M_{a}\right)$} & \multirow{2}{*}{$\frac{d}{d t}\left(v \frac{d p}{d t}\right)$} & \multirow{2}{*}{ Cosat. } \\
\hline & Sample 1 & Sample 3 & Sample 4 & & \\
\hline $\begin{array}{l}\circ K \\
165 \\
170 \\
175 \\
180 \\
185\end{array}$ & $\begin{array}{c}\text { Int. } j g^{-1}{ }^{\circ} K^{-1} \\
1.9104 \\
1.9116 \\
1.9139 \\
1.9172 \\
1.9214\end{array}$ & $\begin{array}{c}\text { Int. } j g^{-1}{ }^{\circ} K^{-1} \\
1.9099 \\
1.9116 \\
1.9141 \\
1.9172 \\
1.9211\end{array}$ & $\begin{array}{c}\text { Int. } j g^{-1}{ }^{\circ} K^{-1} \\
1.9130 \\
1.9136 \\
1.9151 \\
1.9177 \\
1.9213\end{array}$ & $\begin{array}{c}\text { Int. } j g^{-1}{ }^{\circ} K^{-1} \\
0.000 \\
.000 \\
.001 \\
.001 \\
.001\end{array}$ & $\begin{array}{c}\text { Int. } j g^{-1}{ }^{\circ} K^{-1} \\
\text { 1. } 911 \\
\text { 1. } 912 \\
\text { 1. } 915 \\
\text { 1. } 918 \\
\quad 1.922\end{array}$ \\
\hline $\begin{array}{l}190 \\
195 \\
200 \\
205 \\
210\end{array}$ & $\begin{array}{l}1.9262 \\
1.9319 \\
1.9387 \\
1.9459 \\
1.9542\end{array}$ & $\begin{array}{l}\text { 1. } 9257 \\
1.9311 \\
1.9379 \\
1.9454 \\
1.9539\end{array}$ & $\begin{array}{l}1.9258 \\
1.9317 \\
1.9387 \\
1.9467 \\
1.9557\end{array}$ & $\begin{array}{l}.002 \\
.002 \\
.003 \\
.004 \\
.006\end{array}$ & $\begin{array}{l}\text { 1. } 928 \\
\text { 1. } 934 \\
\text { 1. } 941 \\
\text { 1. } 950 \\
1.961\end{array}$ \\
\hline $\begin{array}{l}215 \\
220 \\
225 \\
230 \\
235\end{array}$ & $\begin{array}{l}1.9650 \\
1.9735 \\
1.9837 \\
1.9943 \\
2.0055\end{array}$ & $\begin{array}{l}\text { 1. } 9657 \\
1.9744 \\
1.9854 \\
1.9964 \\
2.0078\end{array}$ & $\begin{array}{c}1.9657 \\
\end{array}$ & $\begin{array}{l}.008 \\
.009 \\
.012 \\
.015 \\
.018\end{array}$ & $\begin{array}{l}1.973 \\
1.983 \\
1.997 \\
2.010 \\
2.025\end{array}$ \\
\hline $\begin{array}{l}240 \\
245 \\
250 \\
255 \\
260\end{array}$ & $\begin{array}{l}\text { 2. } 0168 \\
2.0284 \\
2.0414 \\
2.0529 \\
2.0661\end{array}$ & $\begin{array}{r}2.0192 \\
2.0308 \\
2.0440 \\
2.0551 \\
\end{array}$ & מ & $\begin{array}{l}.021 \\
.025 \\
.030 \\
.035 \\
.041\end{array}$ & $\begin{array}{l}2.039 \\
2.055 \\
2.073 \\
2.089 \\
2.107\end{array}$ \\
\hline $\begin{array}{l}265 \\
270 \\
275 \\
280 \\
285\end{array}$ & $\begin{array}{l}2.0794 \\
2.0934 \\
2.1079 \\
2.1227 \\
2.1377\end{array}$ & - & - & $\begin{array}{l}.047 \\
.054 \\
.062 \\
.070 \\
.080\end{array}$ & $\begin{array}{l}2.126 \\
2.147 \\
2.170 \\
2.193 \\
2.218\end{array}$ \\
\hline $\begin{array}{l}290 \\
295 \\
300\end{array}$ & $\begin{array}{l}2.1530 \\
2.1684 \\
2.1840\end{array}$ & - & - & $\begin{array}{l}.090 \\
.101 \\
.112\end{array}$ & $\begin{array}{l}\text { 2. } 243 \\
\text { 2. } 269 \\
\text { 2. } 296\end{array}$ \\
\hline
\end{tabular}


In table 1 values of specific heat at 5 -degree intervals at saturation are given for the different samples of butadiene in the solid state. Table 2 gives values at 5 -degree intervals of $\left(G_{b}-G_{a}\right) /\left(M_{b}-M_{a}\right)$ for the three samples in the liquid state together with values of $T \frac{d}{d T}\left(v \frac{d P}{d T}\right)$. The values of $C_{\text {sat }}$. in table 2 were obtained by averaging the values of $\left(G_{b}-G_{a}\right) /\left(M_{b}-M_{a}\right)$ at each temperature and adding the value of $T \frac{d}{d T}\left(v \frac{d P}{d T}\right)$

\section{HEAT OF FUSION}

(a) METHOD OF MEASUREMENT

The heat of fusion of butadiene was determined by measuring the energy required to heat the calorimeter and contents from a temperature somewhat below the triple point to a temperature above the triple point. The initial temperature was chosen so as to be below the premelting region. The heat of fusion was obtained by subtracting from the total energy (1) the energy required to heat the calorimeter plus its solid contents from the initial temperature to the melting temperature, and (2) the energy required to heat the calorimeter plus its liquid contents from the melting temperature to the final temperature. In computing quantity (1), the specific heat of pure butadiene was used in obtaining the heat capacity of the calorimeter and contents so as to avoid errors that may be caused by the premelting of impure samples. In this way the heat of premelting is included in the value obtained for the heat of fusion. The heat of fusion was from 60 to 90 percent of the total energy added in the measurements on the different samples.

\section{(b) RESULTS}

The results of the determinations of the heats of fusion are as follows: Sample 1, 147.53; sample 3, 147.59; sample 4, 147.65 int. $\mathrm{j} \mathrm{g}^{-1}$. The mean of these values is 147.59 int. $\mathrm{j} \mathrm{g}^{-1}$. It may be noted that there is little difference in the heats of fusion of the samples, although they contain different amounts of impurity. The scattering of the results is no more than would be expected from ordinary errors of observation. Assigning a reasonable probable error, the heat of fusion of butadiene may be given as $147.6+0.1$ int. $\mathrm{j} \mathrm{g}^{-1}$, or $1908.4 \pm 1.3$ cal mole ${ }^{-1}$.

\section{HEAT OF VAPORIZATION}

(a) METHOD OF MEASUREMENT

The measurement of the heat of vaporization consisted of determining the amount of electric energy required to vaporize a measured quantity of butadiene. This was accomplished in the following manner:

Referring to figure 3 , the reservoirs, $F_{1}$ and $F_{2}$, were cooled by surrounding them with solid $\mathrm{CO}_{2}$. The calorimeter was brought to the desired temperature and the shields adjusted to adiabatic conditions. Then the switch was closed, sending current through the calorimeter heater. The valve leading to $F_{2}$ was opened, and the valve leading to the calorimeter was used as a throttle and adjusted until the temperature of the calorimeter was almost constant. A final adjustment of the current through the calorimeter was necessary to obtain a steady temperature. After equilibrium had been established, the 
valve leading to $F_{2}$ was closed and the valve to $F_{1}$ was opened without disturbing the adjustment of the throttling valve. After a measured interval of time, the valve to $F_{1}$ was closed and the calorimeter heater turned off. The amount of butadiene vapor removed from the calorimeter during the measured time was determined by weighing $F_{1}$ before and after each run. The temperature of the calorimeter was kept constant during a run by making small adjustments of the heating current at measured times, so that the total energy input could be measured by measuring the current and potential drop through the heater during each interval of time between these adjustments. The adjustments of heating current were of the order of 1 percent, and usually several minutes would elapse between adjustments. The platinum resistance thermometer was assumed to be at the temperature of the vaporizing liquid. This may not be strictly true, but if errors arise from this source they should be dependent on the power input, and no such dependence was observed. As the time of withdrawal of the measured sample is determined by manual operation of the valves, the error in timing may be as large as one-half second. The time of withdrawal ranged from 15 to 40 minutes.

\section{(b) RESULTS}

If $Q$ is the energy input during the withdrawal of $M$ grams of vapor, the heat of vaporization $L_{v}$ is

$$
L_{v}=\frac{Q}{M}\left(1-\frac{v}{V}\right)
$$

where $v$ is the specific volume of the liquid, and $V$ is the specific volume of the vapor. $Q / M$ is not the true heat of vaporization as part of the material vaporized does not leave the calorimeter but fills the space vacated by the vaporized liquid.

Table 3 gives the data and results on the heats of vaporization. The energy input, $Q$, and the mass withdrawn, $M$, are given for each individual vaporization at a given temperature, and the quantity $Q / M$ is computed. In order to obtain the mean value of $Q / M$ for each temperature the sum of the energy input was divided by the total amount withdrawn. This is shown in the bottom line of each group of measurements. This mean value is equivalent to that which would have been obtained by weighting the individual observations in proportion to the amount of butadiene vaporized. In calculating the latent heat, $L_{v}=\frac{Q}{M}\left(1-\frac{v}{V}\right)$, values of $v$ and $V$ were taken from table 13. The average deviations of the observations from the mean value of $Q / M$ are given in the next to last column of table 3 . These range from 0.04 to 0.06 percent, and the maximum deviation of a single observation is 0.20 percent. 
TABLE 3.-Data and results of heat-of-vaporization experiments

\begin{tabular}{|c|c|c|c|c|c|c|c|c|}
\hline$T$ & $Q$ & $M$ & $Q / M$ & $\begin{array}{l}\text { Power } \\
\text { input }\end{array}$ & $1-\frac{v}{V}$ & $\begin{array}{l}L_{0}=Q / M \\
\left(1-\frac{v}{V}\right)\end{array}$ & $\begin{array}{c}\text { Average } \\
\text { deviation } \\
\text { of obser- } \\
\text { vations }\end{array}$ & $\begin{array}{c}L, \text { cal- } \\
\text { culated } \\
\text { from } \\
\text { table } 13\end{array}$ \\
\hline 247.07 & $\left\{\begin{array}{r}\text { Int. } j \\
2043.3 \\
1282.2 \\
884.9 \\
915.1 \\
1708.4 \\
2324.6\end{array}\right.$ & $\begin{array}{l}g \\
4.6846 \\
2.9307 \\
2.0267 \\
2.0970 \\
3.9128 \\
5.3246\end{array}$ & $\begin{array}{r}\text { Int. } j g^{-1} \\
436.17 \\
437.50 \\
436.62 \\
436.39 \\
436.62 \\
436.58\end{array}$ & $\begin{array}{l}w \\
1.17 \\
1.19 \\
0.74 \\
0.76 \\
1.78 \\
2.58\end{array}$ & 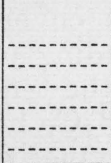 & $\begin{array}{c}\text { Int } j \sigma^{-1} \\
\end{array}$ & $\begin{array}{c}\text { Int. } j g^{1} \\
\\
\\
\\
\\
\end{array}$ & $\begin{array}{l}\text { Int. } j g^{-1} \\
\\
\\
\end{array}$ \\
\hline Total. & 9158.5 & 20.9764 & 436.61 & ....... & 0.99843 & 435.92 & 0.27 & 435. 21 \\
\hline 268.60 & $\left\{\begin{array}{l}1552.2 \\
3616.3 \\
2405.2 \\
1801.8 \\
1878.8\end{array}\right.$ & $\begin{array}{l}\text { 3. } 7147 \\
8.6651 \\
5.7582 \\
4.3165 \\
4.4975\end{array}$ & $\begin{array}{l}417.85 \\
417.34 \\
417.70 \\
417.42 \\
417.74\end{array}$ & $\begin{array}{l}0.86 \\
2.08 \\
0.93 \\
2.00 \\
1.01\end{array}$ & 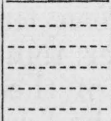 & 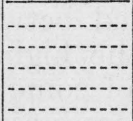 & 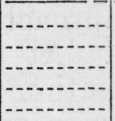 & 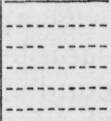 \\
\hline Total.- & 11254.3 & 26.9520 & 417.57 & .......... & 0.99610 & 415.99 & 0.19 & 415.47 \\
\hline 295.67 & $\left\{\begin{array}{l}2594.4 \\
2286.0 \\
1128.4 \\
2324.2 \\
2709.6\end{array}\right.$ & $\begin{array}{l}6.6222 \\
5.8263 \\
2.8801 \\
5.9312 \\
6.9174\end{array}$ & $\begin{array}{l}391.77 \\
392.36 \\
391.79 \\
391.86 \\
391.71\end{array}$ & $\begin{array}{l}1.05 \\
2.54 \\
0.99 \\
2.15 \\
2.66\end{array}$ & 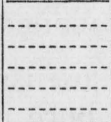 & 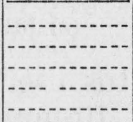 & 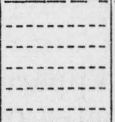 & 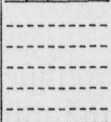 \\
\hline Total... & 11042.6 & 28.1772 & 391.90 & & 0.99012 & 388.03 & 0.20 & 388.17 \\
\hline
\end{tabular}

The formulated values of $L$ (see section VI-2) at temperatures of even degree centigrade (table 13) lead through interpolation to the values given in the last column of table 3. The agreement at $295.67^{\circ} \mathrm{K}$ is excellent, the calculated value being slightly higher than the observed. The calculated values at $268.60^{\circ}$ and $247.07^{\circ} \mathrm{K}$ are only 0.13 and 0.16 percent lower than the respective observed values.

\section{ACCURACY OF CALORIMETRIC MEASUREMENTS}

Some tests were made with the calorimeter to determine the accuracy with which measurements could be made. Water was chosen as the test material as very reliable data [12] are available. The specific heat of water was measured in the calorimeter between $1^{\circ}$ and $22^{\circ} \mathrm{C}$. Three heats were made in this range of temperatures, and the maximum difference between the values obtained and those given by Osborne, Stimson, and Ginnings was 0.03 percent. Three determinations of the heat of vaporization of water at $20^{\circ} \mathrm{C}$ yielded a maximum difference of 0.17 percent, although the mean of the three measurements agreed with Osborne's values to 0.03 percent. The measurements on the specific heat of water are probably somewhat more reliable than those obtained on substances having lower specific heats, as the heat capacity of the water sample is a larger fraction of the total heat capacity of the calorimeter plus contents than it is for other substances. The measurements of the heat of vaporization of water, however, are probably comparable with the measurements on butadiene. The heating rates and total energy input during heats were about the same for the two substances.

Taking into consideration these tests, and the scattering of the observations previously mentioned, the estimates of the probable errors of the calorimetric measurements described in this paper are as follows: Specific heat, 0.1 percent between $40^{\circ}$ and $300^{\circ} \mathrm{K}$, becoming possibly as large as 1 percent below $20^{\circ} \mathrm{K}$; heat of fusion, 0.07 percent; heat of vaporization, 0.15 percent. 


\section{PRESSURE-VOLUME-TEMPERATURE MEASUREMENTS}

\section{VAPOR PRESSURE}

The vapor-pressure measurements comprised two groups of observations made with two independent sets of apparatus. The first group of observations covered a temperature range from $195^{\circ}$ to $288^{\circ} \mathrm{K}$ or a corresponding pressure range up to about $2 \mathrm{~atm}$. The second group covered the temperature range $0^{\circ} \mathrm{C}$ to the critical temperature. Above $110^{\circ} \mathrm{C}$, however, the accuracy was reduced considerably by rapid polymerization of the sample. The method used in both series of measurements was that in which static equilibrium was approached between the liquid and the vapor portions of the sample. At the higher temperatures the approach was always by condensation of some of the sample rather than by evaporation, as the former procedure had been found to be more rapid with other substances.

(a) MEASUREMENTS FROM $195^{\circ}$ TO $288^{\circ} \mathrm{K}$

The apparatus used for these observations consisted of a mercury manometer of $10-\mathrm{mm}$ bore, which was read by means of a mirror-

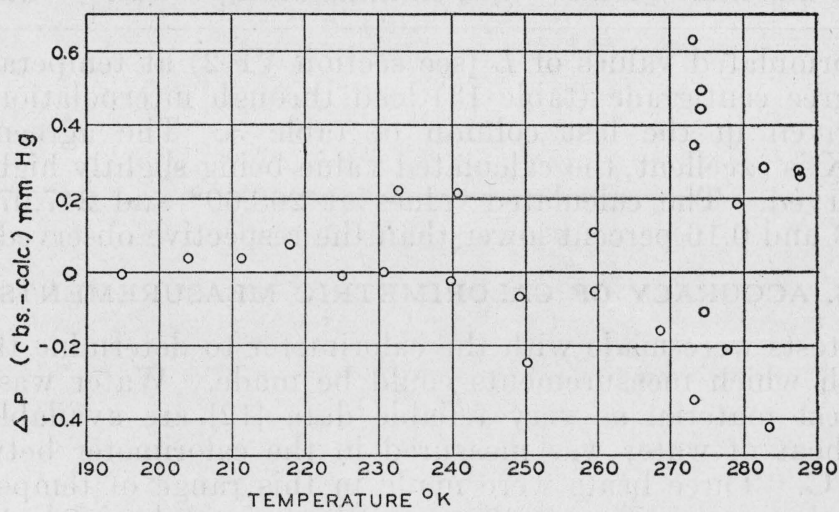

FIGURE 8.-Comparison of vapor pressures observed in the first group of measurements with calculated values.

backed glass scale graduated in millimeters and supported against the manometer tubes. One arm of the manometer was connected to the filler tube of the calorimeter, in which there was a quantity of butadiene from sample 4 . When making measurements of vapor pressures below $1 \mathrm{~atm}$ the other arm of the manometer was evacuated. For measurements above $1 \mathrm{~atm}$ this arm was open to the atmosphere. In the latter case, one measurement of the atmospheric pressure was made with a precision barometer for each set of three readings of the manometer at a given temperature.

Figure 8 shows the deviations of the observations from the values calculated from equation 4 . It was thought that the pressure measurements were reproducible to about $\pm 0.2 \mathrm{~mm} \mathrm{Hg}$. The deviations below $270^{\circ} \mathrm{K}$ confirm this. However, above this temperature there is considerably greater scattering, which has been attributed to the presence of some impurity, causing the vapor pressure to depend on the amount condensed, as described in the section on purity. 
(b) MEASUREMENTS FROM $0^{\circ}$ TO $152^{\circ} \mathrm{C}$

The apparatus used in these measurements was entirely independent of that used in the group (a) measurements made in connection with the calorimetric experiments.

It is shown diagrammatically in figure 9. The vapor pressure of the butadiene in the closed end of one manometer is transmitted through the mercury and oil to either an open-ended auxiliary mercury manometer for the low-pressure measurements or to a deadweight piston gage for the high-pressure measurements [14].

As static vapor-pressure measurements are susceptible to errors due to more volatile impurities, provision was made to vary the butadiene vapor space so that the vapor-pressure measurements could be extrapolated to large vapor volumes. The vapor space was varied

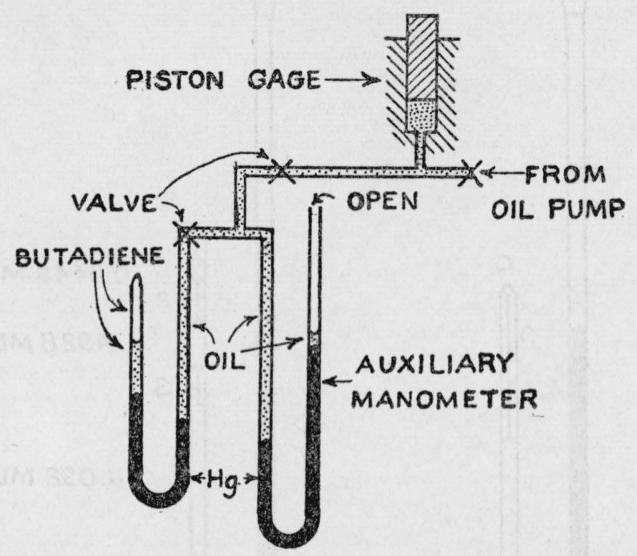

Figure 9.-Connecting lines for vapor pressure measurements.

by changing the amount of oil between the mercury manometers by means of the piston-gage oil pump.

Two types of manometers containing the butadiene were used and are shown in figure 10. Each consisted of a U-shaped glass tube with a metal valve soldered [13] to one arm. In the manometer shown in figure $10, A$, the butadiene was distilled into a space above the mercury meniscus and sealed at $C$. In figure $10, B$, the butadiene was distilled through a small third arm and sealed at $D$. By closing the main portion of the manometer with a mercury seal before sealing the glass, any gases freed during the sealing off and not removed by the vacuum pump were trapped at $D$. In the sealing of both types of manometers the butadiene was cooled with liquid air. The manometer shown in figure $10, B$, was made with calibrated volumes as shown, and could also be used later in the measurement of vapor density.

The small size of the samples used in this group of observations necessitated great care in regard to the cleanliness of the apparatus. The glass manometers were washed with nitric acid, soaked several hours with freshly prepared chromic acid, and rinsed several times with 
distilled water. The last rinse water, which remained in the manometers several hours, had substantially the same electric conductivity as the distilled water used. The manometers were outgassed by heating with a torch during evacuation, and the mercury was introduced by distillation. A small quantity of butadiene was admitted and then pumped out before condensing a sample into a manometer.

For the measurement at $0^{\circ} \mathrm{C}$, the butadiene was completely im-

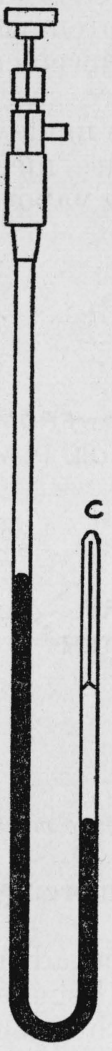

A

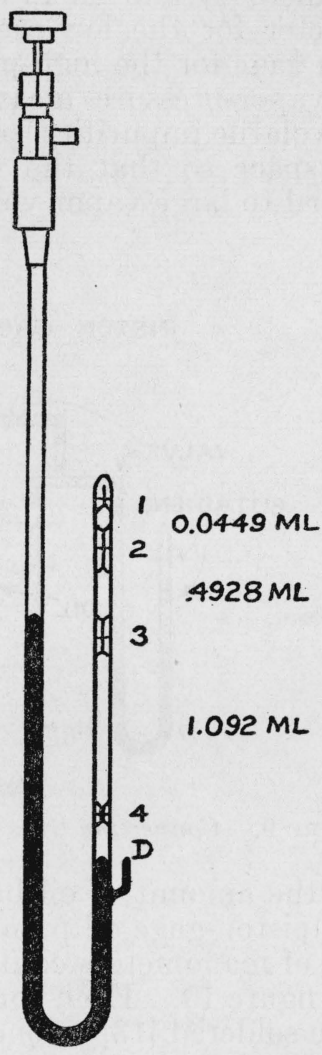

B

Figure 10.-Manometers used in measurements of vapor pressure and of density of vapor.

mersed in an ice bath. At higher temperatures, a stirred thermoregulated oil bath was used. Temperatures were measured with a fourlead, potential-terminal, platinum resistance thermometer of the coiled-filament type, calibrated according to specifications of the International Temperature Scale [15]. The elevations of the mercury surfaces were referred to steel scales graduated in millimeters and suspended between the arms of the manometers.

Seven samples were at various times distilled into manometers for these vapor-pressure measurements. The first five were subsamples taken from sample 3 , already described in the section on preparation of samples, and were numbered $3 \mathrm{a}, 3 \mathrm{~b}, 3 \mathrm{c}, 3 \mathrm{~d}$, and $3 \mathrm{e}$, respectively. The other two (4a and $4 b$ ) were taken from sample 4 . 
The results of the measurements on samples $3 \mathrm{~b}, 3 \mathrm{e}$, and $4 \mathrm{~b}$ are presented in figures 11,12 , and 13 , respectively, in which the abscissas represent the volume occupied per gram of sample, whereas the ordinates represent pressures in centimeters of mercury corrected to $0^{\circ} \mathrm{C}$ and to standard gravity. In order to represent several isotherms with the same coordinates, a constant of appropriate amount for each isotherm is subtracted from the pressures. Observed values are represented in the three figures by various symbols, the same symbol being used uniformly for any one isotherm, calculated values are represented by black squares, the vapor pressure being calculated from vapor-pressure equation 4, and the corresponding volume being calculated from the equation of state 6 . At $0^{\circ} \mathrm{C}$ the specific volume of the vapor $(336 \mathrm{ml} / \mathrm{g})$ is considerably off the scale.

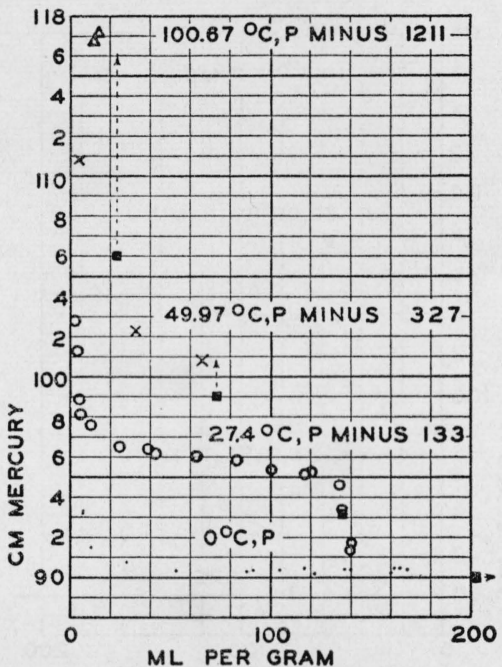

FigURE 11.-Vapor-pressure data forlsample

=Values of pressure calculated from vapor pressure equation 11 and values of specific volume of saturated vapor calculated from equation of state 13 . Specific volume at $0^{\circ} \mathrm{C}=335 \mathrm{ml} / \mathrm{g}$. Dotted line and arrow indicate temperature to which 담 symbol belongs. Other symbols represent observed values.

The data at $0^{\circ} \mathrm{C}$ consist of numerous observations made initially on each sample, followed by observations at higher temperatures, with occasional repeated observations at $0^{\circ} \mathrm{C}$. Such repeated observations after $62^{\circ} \mathrm{C}$ for samples $3 \mathrm{e}$ and $4 \mathrm{~b}$ and after $112^{\circ} \mathrm{C}$ for sample $3 \mathrm{e}$ are represented in figures 12 and 13 by the same symbols as earlier measurements at $0^{\circ} \mathrm{C}$. As their positions in the figures do not distinguish them from earlier measurements, it is believed that polymerization was thus far negligible. The agreement between the vapor pressures of the purer samples also indicates that at temperatures up to and including $112^{\circ} \mathrm{C}$ polymerization caused no appreciable effect.

Of the first four samples, which were not as pure as the others, only the data on sample $3 \mathrm{~b}$ are presented. Besides comprising most of the data above $100^{\circ} \mathrm{C}$, they are of special interest, as this sample was the only one in a manometer of sufficient capacity to permit the complete evaporation of the sample at room temperature, thus furnishing a better illustration of the variation of pressure with volume. The observed values for the vapor pressure of this sample (fig. 11) are 
noticeably higher than the calculated. These differences are attributed to volatile impurities. On the other hand, the observed vapor pressure, $31,945 \mathrm{~mm}$, at $152^{\circ} \mathrm{C}$ (not shown in fig. 11) is low by $484 \mathrm{~mm}$, at least partially due to the extremely rapid rate of polymerization at this temperature.

Two observed values of vapor pressure at $62.05^{\circ} \mathrm{C}$ for sample $3 \mathrm{e}$ (see fig. 12) are notable for being considerably below the calculated pressure, even though the volume of sample was in one case slightly less than that calculated for saturated vapor. This is probably due to an impurity less volatile than butadiene, which appears to be absent in sample $4 \mathrm{~b}$ (see fig. 13).

In addition to these data the vapor pressure of sample $4 \mathrm{a}$ was measured at $0^{\circ}, 99.88^{\circ} \mathrm{C}$, and at the critical temperature (discussed

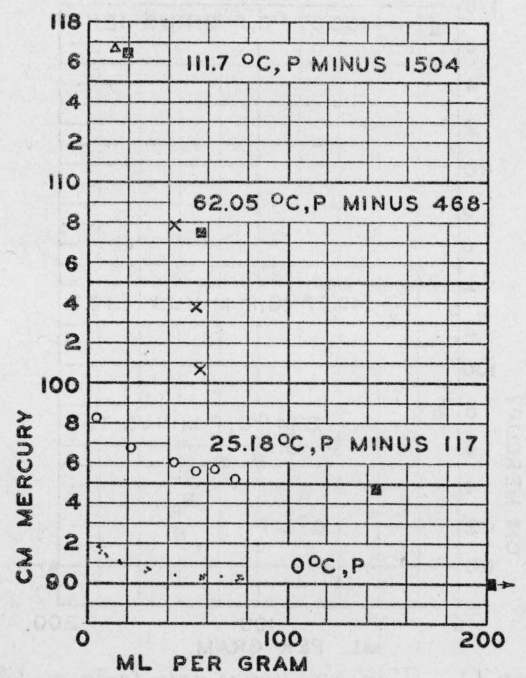

FigURe 12.-Vapor-pressure data for sample Be.

장 =Values of pressure calculated from vapor-pressure equation 11 and values of specific volume of saturated vapor calculated from equation of state 13 . Specific volume at $0^{\circ}=335 \mathrm{ml} / \mathrm{g}$. Other symbols represent observed values.

later). The observed values corresponding to the first two temperatures, $902.0 \mathrm{~mm}$ and $12,973 \mathrm{~mm}$, are in very good agreement with the respective values calculated from the vapor-pressure equation, namely 899.7 and $12,971 \mathrm{~mm}$, especially when one considers that observations with this sample at $0^{\circ} \mathrm{C}$ were possible only with a small portion evaporated on account of the relatively large mass of sample.

The results of these measurements show that the observed vapor pressures depended somewhat on the relative amounts of the sample that were in the liquid and vapor phases. This indicates the presence of an impurity. The data show that the first four samples, $3 \mathrm{a}, 3 \mathrm{~b}$, $3 \mathrm{c}$, and $3 \mathrm{~d}$, contained approximately equal percentages of impurity, that sample $3 \mathrm{e}$ contained somewhat less impurity (probably due to the improved method of sealing the sample), and that samples $4 \mathrm{a}$ and $4 \mathrm{~b}$ contained still less impurity (in consequence of a purer sup- 
ply). The accuracy of reading at $0^{\circ} \mathrm{C}$ would lead one to expect results reproducible to within $0.5 \mathrm{~mm}$, but the variation obtained was about three or four times that amount, as may be seen in figure 14, in which the observed pressures for samples $3 \mathrm{e}$ and $4 \mathrm{~b}$ are represented at $0^{\circ} \mathrm{C}$ with a more open scale than in figures 12 and 13 . It would

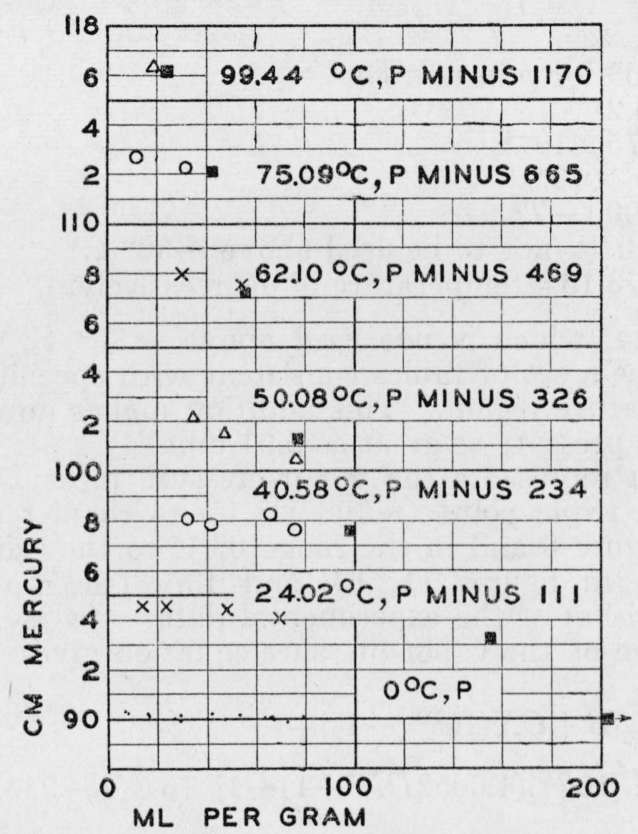

FigURe 13.-Vapor pressure data for sample $4 b$.

Symbols are same as in figure 12 .

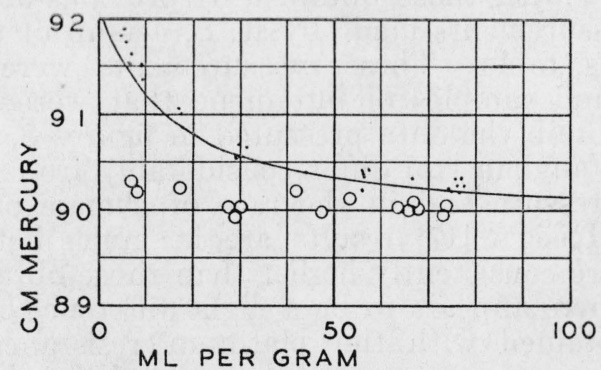

Figdre 14.-Vapor pressure of samples $3 e$ and $4 \mathrm{~b}$ at $0^{\circ} \mathrm{C}$.

appear that the excessive variation was due to a rather large lag in approaching equilibrium. The time required to remove the heat of condensation may have been supplemented by the time required for diffusion of an impurity between the butadiene liquid surface and the remainder of the liquid, especially in the earlier and less pure samples. 
(c) VAPOR-PRESSURE EQUATION

The vapor pressure of 1,3-butadiene is represented over the temperature range from the triple point to the critical temperature by the empirical equation ${ }^{2}$

where

$$
\log p=A-\frac{1}{T}\left[B+C X\left(10^{D X^{2}}-1\right)\right]-E(T-243.16)^{6},
$$

$$
\begin{aligned}
& A=7.2363 \text { for } p \text { in } \mathrm{mm} \mathrm{Hg} \\
& B=1165.21 \\
& C=1.5875 \times 10^{-4} \\
& D=0.766 \times 10^{-10} \\
& X=125,000-T^{2} \\
& \left.E=2 \times 10^{-14} \text { (not to be used above }-30^{\circ} \mathrm{C}\right) \\
& T=t+273.16=\text { temperature in degrees Kelvin. }
\end{aligned}
$$

The last term, which is not used above $-30^{\circ} \mathrm{C}$, was added in order to produce a set of tables consistent with specific-heat data in the low-temperature region. This addition makes no change in the values of vapor pressure as great as $0.01 \mathrm{~mm}$.

The equation represents the vapor-pressure measurements in the range from the triple point $\left(-108.92^{\circ} \mathrm{C}\right)$ to room temperature, as illustrated in figure 8 and in the range $0^{\circ} \mathrm{C}$ to the critical temperature, as shown in figures 11,12 , and 13 . The representation is within the precision of the experimental data.

Differentiation of the vapor-pressure equation gives

$$
\begin{aligned}
\frac{d \ln p}{d T}= & \frac{1}{T^{2}}\left[B+C X\left(10^{D X^{2}}-1\right)\right]+ \\
& 2 C\left[10^{D X^{2}}\left(4.6052 D X^{2}+1\right)-1\right]-6 E(T-243.16)^{5} .
\end{aligned}
$$

(d) COMPARISON WITH DATA OF OTHER OBSERVERS

The values for vapor pressure calculated from equation 4 are compared in table 4 with those obtained by previous observers. Some preliminary measurements made by R. S. Jessup of this Bureau are included in this table. These measurements were made with a Bourdon gage and samples of butadiene that were not as pure as those used to obtain the data presented in figures $8,11,12$, and 13. The results of Vaughan [16] differ considerably from the present results both in pressure and in the rate of change of pressure with temperature. Heisig's [17] results are in much better agreement, although they are consistently higher than those obtained in this investigation. There appears to be a slight difference between Heisig's observations obtained with the platinum resistance thermometer below the freezing temperature of mercury and the observations with a mercury thermometer at higher temperatures. The data obtained

${ }^{2}$ A vapor-pressure equation of the form

$$
\log p=A-{ }_{T}^{1}\left[B+C X\left(10^{\left.D X^{2}-1\right)}\right]\right.
$$

was first used to represent the observed vapor pressures of $\mathrm{CO}_{2}$ within about 3 parts in 10,000 . See BS J. Research 10, 381 (1933) RP538. It has also been used to represent the vapor pressures for several other substances. The value of $X$ is usually approximately $0.7 T_{e}^{2}-T^{2}$, except for those substances having a low critical temperature, in which case the coefficient of $T_{e}^{2}$ is smaller. The value of $C$ for substances previously tried has been between $1.1 \times 10^{-4}$ and $1.22 \times 10^{-4}$. The exceptionally high value obtained for $C$ for butadiene may be a consequence of the lack of accurate vapor-pressure data above $112^{\circ} \mathrm{C}$. 
by Moore and Kanep [18] deviate in an irregular manner, which suggests lack of equilibrium when their observations were made. The normal boiling temperature observed by Lamb and Roper [19] is only slightly lower than that calculated from equation 4 and agrees with that obtained for some of the less pure samples of the present investigation.

TABLE 4.-Comparison of data of other observers with vapor pressures calculated from equation 4

\begin{tabular}{|c|c|c|c|c|c|c|c|c|}
\hline $\begin{array}{l}\text { Tem- } \\
\text { pera- } \\
\text { ture }\end{array}$ & $p_{o b s .}$ & $p_{\text {obs. }}-p_{\text {cal }} l_{c}$ & $\begin{array}{c}\text { Tempera- } \\
\text { ture }\end{array}$ & $p_{\text {obs. }}$. & $p_{o b s .}-p_{c a} l_{c}$ & $\begin{array}{c}\text { Tempera- } \\
\text { ture }\end{array}$ & pobs. & $p_{o b e .}-p_{e a} l_{o}$ \\
\hline \multicolumn{2}{|c|}{ R. S. Jessup. } & Sample 1 & \multicolumn{3}{|c|}{ G. B. Heisig } & \multicolumn{3}{|c|}{ Wm. E. Vaughan } \\
\hline $\begin{array}{r}{ }^{\circ} C_{0} \\
0 \\
25 \\
50 \\
65\end{array}$ & $\begin{array}{r}m m \\
917 \\
2,142 \\
4,340 \\
6,250\end{array}$ & $\begin{array}{ll}m m & \\
& 17 \\
& 37 \\
& 76 \\
& 77\end{array}$ & $\begin{array}{c}{ }^{\circ} C \\
-75.5 \\
-63.4 \\
-51.6 \\
-39.4 \\
-38.6 \\
-32.7 \\
-26.1 \\
-19.9\end{array}$ & $\begin{array}{r}m m \\
14.6 \\
35.4 \\
77.1 \\
153.4 \\
161.7 \\
219.0 \\
301.4 \\
400.5\end{array}$ & $\begin{array}{r}\mathrm{mm} \\
0.2 \\
.1 \\
1.0 \\
0.2 \\
1.8 \\
1.9 \\
1.8 \\
1.6\end{array}$ & $\begin{array}{l}{ }^{\circ} C \\
-81.9 \\
-79.1 \\
-38.5 \\
-24.0 \\
-17.0 \\
-3.1 \\
+0.5\end{array}$ & $\begin{array}{r}m m \\
9.2 \\
11.0 \\
156.9 \\
327.5 \\
442.7 \\
772.4 \\
862.6\end{array}$ & $\begin{array}{r}m m \\
0.8 \\
-3.3 \\
-3.8 \\
-3.2 \\
-10.0 \\
-27.2 \\
-54.1\end{array}$ \\
\hline \multicolumn{2}{|c|}{ R. S. Jessup. } & Sample 2 & $\begin{array}{r}-10.4 \\
-5.6\end{array}$ & $\begin{array}{l}599.9 \\
729.7\end{array}$ & $\begin{array}{l}1.6 \\
4.2\end{array}$ & \multicolumn{3}{|c|}{ G. Moore and E. K. Kanep } \\
\hline \multirow{3}{*}{$\begin{array}{r}0 \\
25 \\
50 \\
65\end{array}$} & \multirow{3}{*}{$\begin{array}{r}904 \\
2,124 \\
4,290 \\
6,210\end{array}$} & \multirow{3}{*}{$\begin{array}{r}4 \\
19 \\
26 \\
37\end{array}$} & & 004. & & \multirow{3}{*}{$\begin{array}{c}-4.5 \\
3.0 \\
10 \\
16 \\
22\end{array}$} & \multirow{3}{*}{$\begin{array}{r}763 \\
957 \\
1,266 \\
1,627 \\
1,926\end{array}$} & \multirow{3}{*}{$\begin{array}{r}6 \\
-49 \\
-24 \\
47 \\
9\end{array}$} \\
\hline & & & \multicolumn{3}{|c|}{ A. B. Lamb and E. E. Roper } & & & \\
\hline & & & -4.51 & 760 & 2.9 & & & \\
\hline
\end{tabular}

\section{DENSITY OF SUPERHEATED VAPOR}

(a) METHOD AND APPARATUS

The density of the superheated vapor was measured for three samples of butadiene $3 \mathrm{~d}, 3 \mathrm{e}$, and $4 \mathrm{~b}$, the first of these being in the manometer illustrated in figure $10 \mathrm{~A}$, and the other two in the manometer illustrated in figure $10 \mathrm{~B}$. The volumes of these manometers were determined by weighing the mercury which filled the right-hand arms to various depths when in an inverted position.

A measured length of capillary in figure $10 \mathrm{~A}$, and the space between marks 1 and 2 in figure $10 \mathrm{~B}$, were used to measure the sample when nearly all condensed. A small vapor space was retained above the liquid to prevent sticking of the liquid in the top of the manometer. It had been previously observed that, after the sample was entirely condensed, the liquid broke away from the top of the manometer only after the pressure had been reduced considerably below the vapor pressure, and the violence of the separation was sufficient to scatter mercury droplets into undesirable places. In addition to this method of measuring the volume of the liquid and estimating the mass of sample from the known density, volume (about $120 \mathrm{ml}$ ), pressure, and temperature of the vapor were observed before the sample was condensed into the manometer. A correction was applied for the deviation from the ideal-gas law. This correction amounted to 1.5 parts in 1,000 for sample $3 \mathrm{~d}$, and 2.4 parts in 1,000 for samples $3 e$ and $4 \mathrm{~b}$, which were filled with a charge at higher pressures than was sample $3 \mathrm{~d}$. 
The measurements of vapor density may be divided into two classes. In the first class are a few measurements in which the vapor occupied the space down to either mark 3 or 4 (see fig. 10 and accompanying discussion in the text). In the second class are a larger number of measurements in which the vapor extends to unmarked parts of the manometers. This latter class of measurements is less accurate than the first. For sample $3 \mathrm{~d}$ the position of only the dome of the meniscus was observed, whereas for samples $3 e$ and $4 \mathrm{~b}$, both the dome and the edge of the meniscus were located with consequent improvement in accuracy.

\section{(b) RESULTS OF MEASUREMENTS AND THEIR FORMULATION}

The results of the measurements on samples $3 \mathrm{~d}, 3 \mathrm{e}$, and $4 \mathrm{~b}$ are presented in tables 5,6 , and 7 , respectively, together with a comparison of the observed values of $p V / R T$ with those calculated from the empirical equation of state $^{3}$

$$
\frac{p V}{R T}=1-\frac{68.4\left[1-10^{-.045(T c / T)^{2}}\right]-1.48}{V}+\frac{6\left(\frac{T_{c}}{T}\right)^{4}+3.5}{V^{2}},
$$

where $v$ is in milliliters per gram, and the other variables are in consistent units. When $p$ is in millimeters of mercury, and $T$ is in degrees Kelvin $\left(T=273.16+{ }^{\circ} C\right)$, the value of $R$ is $1152.95 \mathrm{~mm} \mathrm{Hg}(\mathrm{ml}) / \mathrm{g}$ mole ${ }^{\circ} \mathrm{C}$. Only a few of the differences in tables 5,6 , and 7 exceed an amount appropriate to the accuracy of reading the position of the mercury-butadiene interface (see fig. $10, A$ and $B$ ). The consistent difference between data for samples $3 \mathrm{~d}$ and $3 \mathrm{e}$ does not exceed the uncertainty in determining the mass of sample.

TABLE 5.-Measurements of vapor density for sample $3 d$

Mass of sample by measurement of vapor 0.01591 Mass of sample by measurement of liquid. .01591

Weighted mean value. 0.01591 gram

\begin{tabular}{|c|c|c|c|c|c|c|c|}
\hline Date & $\begin{array}{c}\text { Class of } \\
\text { observation }\end{array}$ & $\begin{array}{l}\text { Temper- } \\
\text { ature }\end{array}$ & Pressure & $\begin{array}{l}\text { Specific } \\
\text { volume }\end{array}$ & $\begin{array}{l}p v / R T \text { ob- } \\
\text { served }\end{array}$ & $\begin{array}{c}p v / R T \text { cal- } \\
\text { culated }\end{array}$ & $10 \frac{\mathrm{col} .6-\mathrm{col} .7}{\mathrm{col} .7}$ \\
\hline 1943 & $\begin{array}{l}2 \\
2 \\
2 \\
2 \\
2 \\
2 \\
2 \\
2\end{array}$ & $\begin{array}{l}{ }^{\circ} C \\
30.78 \\
30.80 \\
30.81 \\
30.80 \\
36.41 \\
36.41 \\
36.41 \\
36.41\end{array}$ & $\begin{array}{c}m m \mathrm{Hg} \\
2206.0 \\
2271.9 \\
2337.8 \\
2470.8 \\
2674.8 \\
2742.7 \\
2844.6 \\
2945.2\end{array}$ & $\begin{array}{l}m l / g \\
147.39 \\
142.86 \\
138.34 \\
130.04 \\
122.31 \\
119.11 \\
114.20 \\
109.43\end{array}$ & $\begin{array}{l}0.9279 \\
.9261 \\
.9228 \\
.9169 \\
.9166 \\
.9153 \\
.9101 \\
.9030\end{array}$ & $\begin{array}{l}0.9260 \\
.9237 \\
.9213 \\
.9165 \\
.9145 \\
.9121 \\
.9086 \\
.9050\end{array}$ & $\begin{array}{r}21 \\
26 \\
16 \\
4 \\
23 \\
35 \\
17 \\
-22\end{array}$ \\
\hline Mar. 3. & $\begin{array}{l}2 \\
2 \\
2 \\
2 \\
2 \\
2 \\
2\end{array}$ & $\begin{array}{r}49.90 \\
49.90 \\
49.90 \\
100.04 \\
99.99 \\
99.95\end{array}$ & $\begin{array}{r}2680.2 \\
3365.6 \\
4062.5 \\
5,509 \\
9,110 \\
12,739\end{array}$ & $\begin{array}{r}129.04 \\
100.64 \\
81.14 \\
71.28 \\
39.09 \\
24.89\end{array}$ & $\begin{array}{l}.9286 \\
.9094 \\
.8850 \\
.9127 \\
.8277 \\
.7372\end{array}$ & $\begin{array}{l}.9256 \\
.9049 \\
.8831 \\
.9041 \\
.8268 \\
.7352\end{array}$ & $\begin{array}{l}33 \\
50 \\
22 \\
95 \\
10 \\
27\end{array}$ \\
\hline erage & & & & & & & 29 \\
\hline
\end{tabular}

${ }^{3}$ Equation 6 expresses $p$ at a given $T$ as a cubic equation in $V$, necessitating the use of successive approximations for calculating the specific volume of the saturated vapor. For the first approximation it was convenient to obtain values of $v[27]$ from the simpler equation

$$
\left(1-\frac{p V}{R T}\right)_{\bullet}=\frac{\left(p / 2.718 p_{c}\right)^{0.702}}{\left(1-\frac{p V}{R T}\right)_{l}},
$$

where the subscripts $g$ and $l$ refer to gas and liquid, respectively, and $p_{c}$ is the critical pressure. 
TABLE 6.-Measurement of vapor density for sample $3 e$

Mass of sample by measurement of vapor. 0.02749

Mass of sample by measurement of liquid

.02741

Weighted mean value-

0.02746 gram.

\begin{tabular}{|c|c|c|c|c|c|c|c|}
\hline Date & $\begin{array}{c}\text { Class of } \\
\text { observation }\end{array}$ & $\begin{array}{l}\text { Temper- } \\
\text { ature }\end{array}$ & Pressure & $\begin{array}{l}\text { Specific } \\
\text { volume }\end{array}$ & $\begin{array}{l}p v / R T \text { ob- } \\
\text { served }\end{array}$ & $\begin{array}{c}p v / R T \text { cal- } \\
\text { culated }\end{array}$ & $10^{4} \frac{\mathrm{col} .6-\mathrm{col} .7}{\mathrm{col} .7}$ \\
\hline 1943 & $\begin{array}{l}2 \\
2 \\
2 \\
2 \\
2 \\
2 \\
2 \\
1\end{array}$ & $\begin{array}{l}{ }^{\circ} C \\
59.64 \\
59.65 \\
59.66 \\
62.03 \\
62.03 \\
62.03 \\
62.03 \\
62.03\end{array}$ & $\begin{array}{c}m m \mathrm{Hg} \\
4283.7 \\
4561.6 \\
5117.6 \\
4287.1 \\
4562.7 \\
4840.9 \\
5120.1 \\
5544.9\end{array}$ & $\begin{array}{r}m l / g \\
79.24 \\
73.78 \\
64.79 \\
80.12 \\
74.58 \\
69.77 \\
65.44 \\
59.47\end{array}$ & $\begin{array}{l}0.8847 \\
.8771 \\
.8641 \\
.8888 \\
.8806 \\
.8740 \\
.8670 \\
.8533\end{array}$ & $\begin{array}{r}0.8881 \\
.8800 \\
.8635 \\
.8908 \\
.8830 \\
.8750 \\
.8669 \\
.8541\end{array}$ & $\begin{array}{r}-39 \\
-33 \\
+7 \\
-22 \\
-27 \\
-12 \\
+1 \\
-9\end{array}$ \\
\hline April 3. & $\begin{array}{l}2 \\
1 \\
2 \\
2 \\
1\end{array}$ & $\begin{array}{l}111.71 \\
111.71 \\
111.70 \\
111.71 \\
111.71\end{array}$ & $\begin{array}{r}5588.3 \\
6665.5 \\
9143.2 \\
12,755 \\
15,649\end{array}$ & $\begin{array}{l}72.25 \\
59.43 \\
40.93 \\
26.91 \\
19.70\end{array}$ & $\begin{array}{l}.9099 \\
.8928 \\
.8434 \\
.7735 \\
.6948\end{array}$ & $\begin{array}{l}.9106 \\
.8917 \\
.8455 \\
.7693 \\
.6937\end{array}$ & $\begin{array}{r}-8 \\
+12 \\
-25 \\
+55 \\
+16\end{array}$ \\
\hline rerage & $\begin{array}{l}\text { class 1.- } \\
\text { class 2 }\end{array}$ & & & & & & $\begin{array}{l}10 \\
23\end{array}$ \\
\hline
\end{tabular}

TABLE 7.-Measurement of vapor density for sample $4 b$

Mass of sample by measurement of vapor

Mass of sample by measurement of liquid.

Weighted mean value.

0.02750 gram

\begin{tabular}{|c|c|c|c|c|c|c|c|}
\hline Date & $\begin{array}{c}\text { Class of } \\
\text { observation }\end{array}$ & $\begin{array}{l}\text { Temper- } \\
\text { ature }\end{array}$ & Pressure & $\begin{array}{l}\text { Specific } \\
\text { volume }\end{array}$ & $\begin{array}{l}p v / R T \text { ob- } \\
\text { served }\end{array}$ & $\begin{array}{l}p v / R T \text { cal- } \\
\text { culated }\end{array}$ & $10 \frac{\operatorname{col} .6-\operatorname{col} .7}{\mathrm{col} .7}$ \\
\hline \multirow[t]{2}{*}{1943} & $\begin{array}{l}2 \\
2 \\
2 \\
1\end{array}$ & $\begin{array}{l}\circ C \\
\circ 50.08 \\
50.08 \\
62.10 \\
62.10\end{array}$ & $\begin{array}{r}m m \mathrm{Hg} \\
4,060 \\
4,264 \\
4,288 \\
5,557\end{array}$ & $\begin{array}{l}m l^{\prime} / g \\
80.87 \\
76.15 \\
80.43 \\
59.37\end{array}$ & $\begin{array}{r}0.8811 \\
.8713 \\
.8922 \\
.8536\end{array}$ & $\begin{array}{r}0.8831 \\
.8765 \\
.8910 \\
.8540\end{array}$ & $\begin{array}{r}-23 \\
-60 \\
+13 \\
+5\end{array}$ \\
\hline & $\begin{array}{l}2 \\
1 \\
2 \\
2 \\
1 \\
2 \\
2 \\
2 \\
1 \\
2 \\
1 \\
2 \\
2 \\
2 \\
2 \\
2 \\
2 \\
2 \\
2 \\
2\end{array}$ & $\begin{array}{r}75.09 \\
75.08 \\
75.08 \\
99.44 \\
99.44 \\
99.44 \\
99.44 \\
149.00 \\
149.00 \\
149.00 \\
149.00 \\
148.98 \\
148.98 \\
148.98 \\
148.98 \\
148.98 \\
148.98 \\
148.98 \\
148.98 \\
148.98\end{array}$ & $\begin{array}{r}4,350 \\
5,854 \\
6,983 \\
4,717 \\
6,406 \\
9,111 \\
12,724 \\
5,589 \\
7,479 \\
12,745 \\
18,621 \\
22,189 \\
23,637 \\
25,092 \\
25,820 \\
26,548 \\
27,278 \\
28,008 \\
28,736 \\
29,464\end{array}$ & $\begin{array}{r}83.23 \\
59.37 \\
48.43 \\
83.27 \\
59.37 \\
39.27 \\
25.09 \\
81.16 \\
59.38 \\
32.40 \\
19.67 \\
15.09 \\
13.78 \\
11.96 \\
11.38 \\
10.80 \\
10.15 \\
9.53 \\
8.69 \\
7.78\end{array}$ & $\begin{array}{l}.9017 \\
.8657 \\
.8423 \\
.9144 \\
.8854 \\
.8329 \\
.7432 \\
.9315 \\
.9125 \\
.8484 \\
.7526 \\
.6880 \\
.6693 \\
.6166 \\
.6037 \\
.5891 \\
.5689 \\
.5484 \\
.5131 \\
.4710\end{array}$ & $\begin{array}{l}.9029 \\
.8647 \\
.8341 \\
.9163 \\
.8833 \\
.8257 \\
.7344 \\
.9359 \\
.9128 \\
.8437 \\
.7539 \\
.6887 \\
.6587 \\
.6247 \\
.6068 \\
.5872 \\
.5657 \\
.5416 \\
.5124 \\
.4783\end{array}$ & $\begin{array}{r}-13 \\
+12 \\
+98 \\
-21 \\
+24 \\
-34 \\
+120 \\
-47 \\
-3 \\
+56 \\
-17 \\
-10 \\
+160 \\
-133 \\
-52 \\
+33 \\
+39 \\
+125 \\
+14 \\
-155\end{array}$ \\
\hline \multicolumn{7}{|c|}{$\begin{array}{l}\text { Average deviation class } 1 \\
\text { Average deviation class } 2\end{array}$} & $\begin{array}{l}12 \\
63\end{array}$ \\
\hline
\end{tabular}




\section{DENSITY OF SATURATED LIQUID}

(a) METHOD AND APPARATUS

The density of liquid butadiene was measured in the pyrex glass picnometer illustrated in figure 15 . The picnometer was calibrated by weighing the amounts of mercury or water that filled the various parts of the picnometer. The results of these calibrations are given

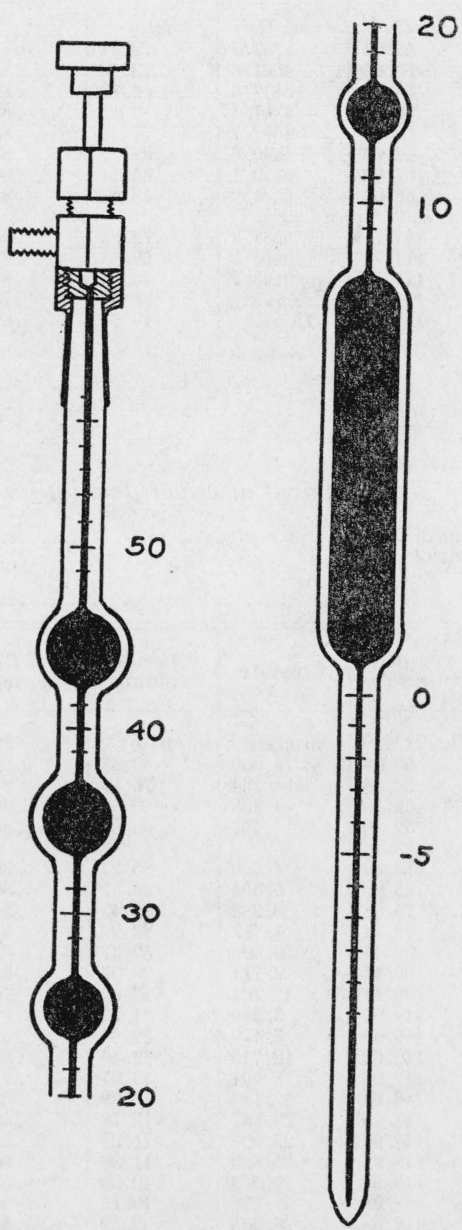

Figure]15.-Semisectional view of picnometer.

in table 8. The worst discrepancy between the two calibrations is at mark 40 , which amounts to about 1 part in 7,000 . The mean value, which is less than 1 part in 10,000 from either calibration, was used in calculating the results. The cross section of the capillary used in the picnometer was measured as an aid in correcting for readings not directly at a mark. The cross section of the capillary portions between the valve and the large bulb is $1.00 \mathrm{~mm}^{2}$, that for the capillary below the large bulb is $1.38 \mathrm{~mm}^{2}$. Both capillaries were calibrated by weighing mercury threads of measured length. 
TABLE 8.-Data from calibration of picnometer

\begin{tabular}{|c|c|c|c|c|}
\hline \multirow[b]{2}{*}{ Space included } & \multicolumn{4}{|c|}{ Capacity at $0^{\circ} \mathrm{C}$} \\
\hline & $\begin{array}{c}\text { Water } \\
\text { calibration } \\
\text { (Sept. 15-16, } \\
\text { 1943) }\end{array}$ & $\begin{array}{l}\text { Mercury } \\
\text { calibration } \\
\text { (Oct. 1-12, } \\
1943 \text { ) }\end{array}$ & Mean & $\begin{array}{c}\text { Total } \\
\text { volume }\end{array}$ \\
\hline $\begin{array}{l}\text { Valve to mark } 50 \\
\text { Mark } 50 \text { to mark } 40 \\
\text { Mark } 40 \text { to mark } 30 \\
\text { Mark } 30 \text { to mark } 20 \\
\text { Mark } 10 \text { to mark } 10 \\
\text { Mark } 0 \text { to bottom } 0\end{array}$ & $\begin{array}{r}m l \\
0.0731 \\
1.8348 \\
1.3442 \\
.8922 \\
.5667 \\
10.8448 \\
.1400\end{array}$ & $\begin{array}{r}m l \\
1.8365 \\
1.3423 \\
.8921 \\
.5665 \\
10.8446\end{array}$ & $\begin{array}{r}m l \\
0.0731 \\
1.8356 \\
1.3433 \\
.8922 \\
.5666 \\
10.8447 \\
.1400\end{array}$ & $\begin{array}{r}m l \\
15.6955 \\
15.6224 \\
13.7868 \\
12.4435 \\
11.5513 \\
10.9847 \\
.1400\end{array}$ \\
\hline
\end{tabular}

The coefficient of volumetric expansion of the picnometer was assumed to be $1.00 \times 10^{-5}$ per degree centigrade. The stretch of the picnometer with pressure, calculated from the dimensions of the large picnometer bulb (18- $\mathrm{mm}$ outside diameter and $1.8-\mathrm{mm}$ wall thickness) and the elastic properties of Pyrex, was $1.61 \times 10^{-5} / \mathrm{atm}$.

The measurement of the density of liquid butadiene was subject to error from polymerization, especially at the higher temperatures. On this account, the densities at low temperatures were observed first and a correction applied to the measurements at higher tempertures. This correction was determined by repeating the measurement at $0^{\circ} \mathrm{C}$ and noting the change in volume at $0^{\circ} \mathrm{C}$ resulting from polymerization at the higher temperature. Two subsamples, 4c and $4 \mathrm{~d}$, were taken from the larger sample 4 for the measurements of liquid density. Except at $-78.72^{\circ} \mathrm{C}$ and at $0^{\circ} \mathrm{C}$, the temperature was measured with the same platinum resistance thermometer used for measuring temperatures during the vapor-pressure investigation (IV-1 b).

Several different baths were used for measuring the density of these samples at various temperatures. At $-78.72^{\circ} \mathrm{C}$ the picnometer was packed in finely divided dry ice up to the level of the meniscus. Precautions were taken to purge air from the space above the solid, and to pack the dry ice thoroughly enough to avoid radiation from the surroundings between the particles of solid $\mathrm{CO}_{2}$. At $95.67^{\circ} \mathrm{C}$ the picnometer was totally immersed in a steam bath operated at a pressure below atmospheric. The data indicated that the temperature of this bath changed too rapidly with time, and in consequence of prolonged efforts to attain equilibrium, the correction for polymerization was unduly large, so that the corrected result is not as reliable as at the other temperatures. At $0^{\circ} \mathrm{C}$ an ice bath of shaved ice packed with enough water to fill the crevices but not to float the ice was used. In order to maintain the butadiene meniscus also at $0^{\circ} \mathrm{C}$ during the observations, a glass sight tube was placed between the picnometer and the bath container and ice was piled over the tube. At the remaining temperatures thermally controlled stirred liquid baths were used.

\section{(b) RESULTS OF MEASUREMENTS AND THEIR FORMULATION}

The data obtained are presented in tables 9 and 10 . In these tables the "volumes occupied" include corrections to the volume of the picnometer at $0^{\circ} \mathrm{C}$ and $1 \mathrm{~atm}$. It is to be noted that the density 
of the vapor given in these tables is not necessarily that of the saturated vapor but that of the vapor existing in the picnometer. The "apparent liquid density" is the quotient obtained by dividing the mass of liquid by the volume occupied. The corrected density was obtained by adding to the apparent density (columns 8 of the tables 9 and 10) the correction for polymerization already discussed.

\section{TABLE 9.-Measurements of liquid density for sample $4 \mathrm{c}$}
Mass of sample by weighing in .... 8.0392
Mass of sample by weighing out ... 8.0390
Mean value.
8. 0391 grams.

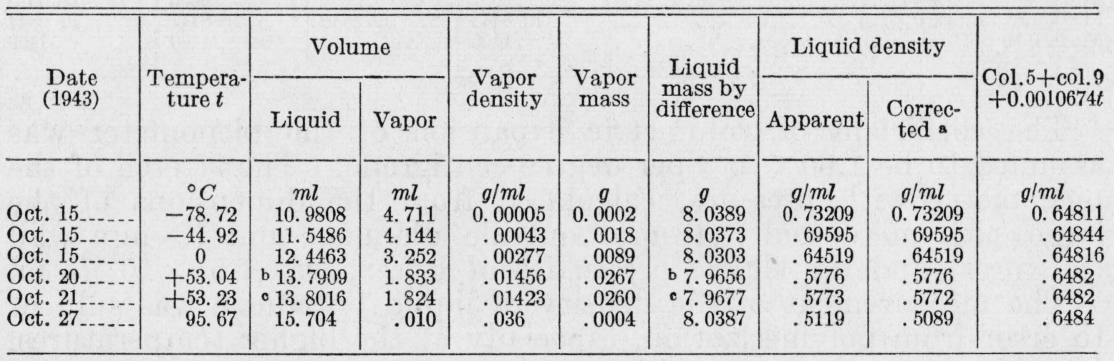

a Corrected for compressibility of liquid and for polymerization.

b Not including 0.0475 gram of liquid in top capillary next to valve.

- Not including 0.0454 gram of liquid in top capillary next to valve.

TABLE 10.-Measurements of liquid density for sample $4 d$

Mass of sample by weighing in _... 7.4635

Mass of sample by weighing out.... 7.4642

Mean value.

7. 4638 grams

\begin{tabular}{|c|c|c|c|c|c|c|c|c|c|}
\hline \multirow{2}{*}{$\begin{array}{l}\text { Date } \\
(1943)\end{array}$} & \multirow{2}{*}{$\begin{array}{l}\text { Tempera- } \\
\text { ture } t\end{array}$} & \multicolumn{2}{|c|}{ Volume } & \multirow{2}{*}{$\begin{array}{l}\text { Vapor } \\
\text { density }\end{array}$} & \multirow{2}{*}{$\begin{array}{l}\text { Vapor } \\
\text { mass }\end{array}$} & \multirow{2}{*}{$\begin{array}{l}\text { Liquid } \\
\text { mass by } \\
\text { difference }\end{array}$} & \multicolumn{2}{|c|}{ Liquid density } & \multirow{2}{*}{$\begin{array}{r}\text { Col. } 5+\text { col. } 9 \\
+0.0010674 t\end{array}$} \\
\hline & & Liquid & Vapor & & & & Apparent & $\begin{array}{l}\text { Correc- } \\
\text { ted a }\end{array}$ & \\
\hline $\begin{array}{l}\text { Nov. } 3 \ldots \\
\text { Nov. } 2 . \\
\text { Nov. } 8 \\
\text { Nov. } 9 .\end{array}$ & $\begin{array}{c}{ }^{\circ} C \\
-29.79 \\
0 \\
+38.73 \\
79.62\end{array}$ & $\begin{array}{l}c m \\
10.9814 \\
11.5494 \\
12.4487 \\
13.794\end{array}$ & $\begin{array}{l}m l \\
4.71 \\
4.146 \\
3.253 \\
1.914\end{array}$ & $\begin{array}{c}g / m l \\
0.00081 \\
.00277 \\
.00961 \\
.02613\end{array}$ & $\begin{array}{c}g \\
0.0038 \\
.0115 \\
.0313 \\
.0500\end{array}$ & $\begin{array}{c}g \\
7.4600 \\
7.4523 \\
7.4325 \\
7.4138\end{array}$ & $\begin{array}{c}g / m l \\
0.67933 \\
.64525 \\
.59705 \\
.53746\end{array}$ & $\begin{array}{c}g / m l \\
0.67933 \\
.64525 \\
.59702 \\
.53709\end{array}$ & $\begin{array}{r}g / m l \\
0.64844 \\
.64822 \\
.64806 \\
.64848\end{array}$ \\
\hline
\end{tabular}

a Corrected for compressibility of liquid and for polymerization.

The rule of the rectilinear diameter by Cailletet and Mathias states that the sum of the densities of the liquid and the vapor is a linear function of temperature. A graph plotted for numerous substances shows that this rule gives a very close approximation if the rate of change with temperature of the sum of the densities is less than -1 , when both variables are expressed in reduced units. The constants given for butadiene by Cragoe [20] lead to the equation

$$
\rho_{l}+\rho_{s}=0.64817-0.0010674 t,
$$

where $\rho_{l}$ and $\rho_{g}$ are the densities of saturated liquid and vapor, respectively, in grams per milliliter and $t$ is the temperature in degrees centigrade. 
It will be seen that the sum of $\rho_{l}, \rho_{g}$, and $0.0010674 t$ should be very nearly constant. Such sums are given in column 10 of tables 9 and 10 and are shown graphically as ordinate with temperature as abscissas in figure 16. The densities of the vapor used for this purpose are calculated from equations 4 and 6 in the same manner as the values in table 15 (discussed in section VII).

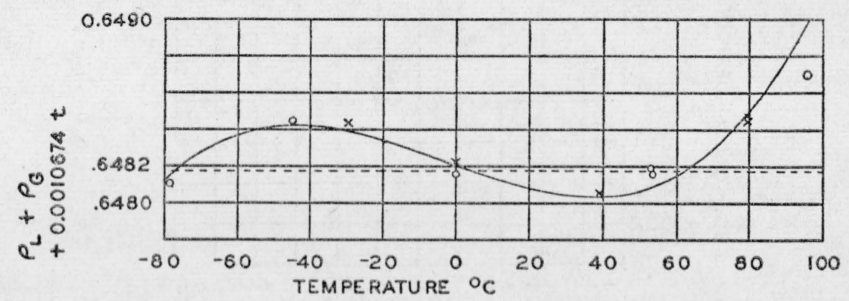

FIGURE 16.-Comparison of observed with calculated densities of liquid 1,S-butadiene.

$$
\begin{aligned}
& \odot=\rho 1 \text { from sample } 4 \mathrm{c} . \\
& \mathrm{X}=\rho \text { from sample 4d. } \\
& \ldots-., \rho 1 \text { from equation } 7 . \\
& \hline, \rho 1 \text { from equation } 8 .
\end{aligned}
$$

The values calculated from equation 7 are represented by the dotted line in figure 16. The differences between the observed values and these calculated values are somewhat greater than the precision of the observed data, which are better represented by the continuous curve. This curve is calculated from the equation

$$
\rho_{l}+\rho_{g}=0.64820-0.0010748 t+1.6 t^{2} 10^{-8}+1.5 t^{3} 10^{-9},
$$

in which the notation is the same as in equation 7 . The constant 0.64820 in this cubic equation corresponds to a liquid density of $0.64523 \mathrm{~g} / \mathrm{ml}$ at $0^{\circ} \mathrm{C}$. This is nearly the mean of the observations on the two samples at $0^{\circ} \mathrm{C}$, and is believed to be correct within a few units in the fifth decimal place. As may be seen from figure 16, equation 8 is in agreement with the observed values within five units in the fifth decimal place in the temperature range $-80^{\circ}$ to $+40^{\circ} \mathrm{C}$. Below $-60^{\circ} \mathrm{C}$ the uncertainty in the expansion of the picnometer is relatively large, and above $+50^{\circ} \mathrm{C}$ the observations are less accurate, in consequence of which the data in that temperature range are not considered accurate beyond the fourth decimal place, and above $100^{\circ} \mathrm{C}$ beyond the third decimal place. Values calculated from equation 8 are given in table 6 (discussed in section VI).

\section{(c) COMPARISON WITH OTHER DATA}

The densities measured by other observers are compared with the values calculated from the present formulation in figure 17. Prevost's [21] value for the density near the boiling point is notably low. The low normal boiling point $\left(-4.75^{\circ} \mathrm{C}\right)$ for his sample suggests the presence of lighter hydrocarbons as impurities, which would explain the low density. The data given in Landolt-Bornstein [22] appear to be smoothed and have been represented by a dotted curve. The present data are intermediate between those from Pennsylvania State College [23] and those by Dean and Legatski [24]. The latter observers heated the surface of their sample above the average tem- 
perature of the sample. In consequence, the liquid was subjected to a pressure exceeding the saturation pressure, and at the higher temperatures, where the liquid is more compressible, the observed densities may be appreciably too high.

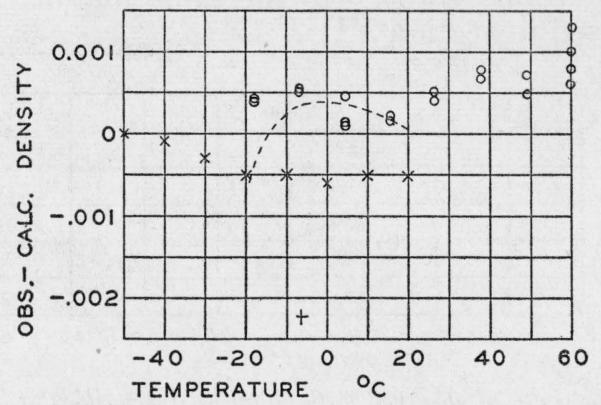

FIGURE 17.-Comparison of values calculated from equation 16 with data of other observers.

$+=$ C. Prevost [19]

$--=$ I. G. Farbenindustrie [20]

$\bar{X}=$ Pennsylvania State College [21]

$\mathrm{O}=\mathrm{M}$. R. Dean and T. W. Legatski [22]

\section{RATE OF POLYMERIZATION}

The observations taken during the measurement of liquid density at $79.6^{\circ} \mathrm{C}$, together with the assumption that the volumes of $1,3-$ butadiene and its dimer are additive upon mixing, lead to a rate of dimerization for pure butadiene of 0.12 percent/hr at $79.6^{\circ} \mathrm{C}$. This is in very good agreement with the value 0.11 percent at $82^{\circ} \mathrm{C}$ found by Robey, Wiese, and Morrell [25], who have made a thorough investigation of the rates of polymerization for pure butadiene and butadiene containing peroxides. It should be noted that in the present work the lower end of the column of butadiene was in contact with mercury, which has been reported to be a catalyst for polymerization [26].

\section{CRITICAL CONSTANTS}

Due to the rapid polymerization of the butadiene samples near the critical state, accurate direct measurement of critical constants was not possible. The procedure near the critical temperature was to start with the sample in the vapor phase and to compress it by steps, observing the pressure after each step and watching for the butadiene meniscus to appear. When sample $3 \mathrm{~b}$ was thus treated at $152.0^{\circ} \mathrm{C}$ the meniscus suddenly appeared in the middle of the sample. At first it was very faint but soon became much more noticeable. Sudden expansion of the sample was accompanied by a transient opalescence, and as the sample was thus evaporated the meniscus took on the appearance of being considerably below the critical temperature. This effect is believed to be due to polymerization. The initial appearance only should be considered, on which basis $152^{\circ} \mathrm{C}$ is very near the critical temperature.

Sample $4 \mathrm{~b}$ was observed at $149.0^{\circ} \mathrm{C}$. The meniscus, very faint at first, appeared near the mercury at a volume considerably greater 
than expected. Although "rain" and "fog" appeared during expansion (a phenomenon characteristic of the region near the critical), the volume at which the meniscus appeared indicated that the specific volume of the saturated vapor was considerably greater than the critical volume, and it was concluded that $149^{\circ} \mathrm{C}$ is below the critical temperature.

Sample 4 a was observed at $157.36^{\circ} \mathrm{C}$. The mass of thesample was unknown, hence only relative volumes were observed, but the pressure measurements are probably the best obtained near the critical state. These data are illustrated in figure 18, in which the upper portion

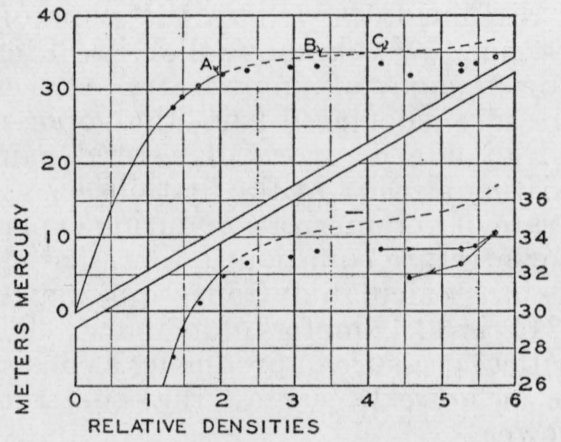

Figure 18.-Isotherm at $157.36^{\circ} \mathrm{C}$ for sample No. $4 \mathrm{a}$.

Upper part-General view of whole isotherm.

Lower part-Magnified pressure scale near critical region.

Continuous curve represents calculated values from equation 13, with the assumption that the lowest observed point is unaffected by polymer ization. Connected straight lines with arrows indicate chronoogical order of experiments.

A meniscus appears near mercury.

$\mathrm{B}$ meniscus disappears near middie of sample leaving opalescent band 1 or $2 \mathrm{~mm}$ wide.

$\mathrm{C}$ opalescent band disappears.

illustrates the whole isotherm and the lower portion illustrates the field covered by the observations with an enlarged pressure scale. After being compressed step by step until the highest density observed was reached, the sample was expanded. To avoid ambiguity, part of the points in figure 18 are connected with straight lines and the chronological order is indicated with arrows. The decrease in pressure indicated by the last two observations is obviously the result of polymerization. The continuous curve represents values calculated from the equation of state 6 , which is believed to be valid up to about half the critical density, the relative volume scale being adjusted to fit the observed pressure at the lowest density. Assuming the value $0.245 \mathrm{~g} \mathrm{ml}^{-1}$ given in table 13 for the critical density, this adjustment places the critical density on the relative scale at approximately 3.7. The dotted curve was then drawn in to illustrate the path that would be expected had there been no polymerization. The course that this dotted curve should follow is uncertain for two reasons: (1) the rate of polymerization varies with the density, and (2) the data do not furnish an estimate of the effect on pressure of this rate except where pressures were observed with the densities varied in both directions. The short horizontal line in figure 18 represents a calculated pressure obtained from equations 4 and 5, together with the assumption that at the critical density, $(d p / d t)_{V}$ has a constant value above the critical temperature $\left(152^{\circ} \mathrm{C}\right)$, an assumption 
made by inference from the behavior of $\mathrm{CO}_{2}$ and other substances with well-known properties.

The point A (fig. 18) represents the relative volume at which a liquid butadiene meniscus appeared near the mercury. At B this meniscus had approached the middle of the sample and vanished, leaving an opalescent band 1 or $2 \mathrm{~mm}$ wide. At $\mathrm{C}$ even this band had vanished without reaching the top of the sample. It may be inferred that the polymer at first condensed to form a solution relatively rich in polymers, the solution becoming diluted with more and more of the monomer until the critical temperature of the solution fell below $157^{\circ} \mathrm{C}$, and the meniscus, and even the opalescent band, vanished. Thus the phenomenon just discussed, as well as the slope of the isotherm in figure 18 , indicates that $157^{\circ} \mathrm{C}$ is above the critical tempera ture of pure butadiene. The discrepancy of about $1 \mathrm{~atm}$ between the isotherm as drawn and the pressure calculated from the vapor-pressure equation can be attributed to one or more of several causes, namely: (1) polymerization existing already at the first observation, (2) an underestimation of the rate of polymerization during experiments, and (3) a failure of the vapor-pressure equation to represent the facts.

The vapor pressure calculated from equation 4 for the critical temperature $\left(152^{\circ} \mathrm{C}\right)$ is 32.42 meters of mercury. This value has been adopted for the critical pressure in producing a consistent set of tables, although the data in figure 18 suggest that the true critical pressure may be slightly lower.

The critical density is best determined from the mean of the data on the density of the liquid and the vapor. Two equations for the mean of these data are given. The linear equation 7 leads to $0.243 \mathrm{~g} / \mathrm{ml}$, whereas the cubic equation 8 leads to $0.245 \mathrm{~g} / \mathrm{ml}$. As the cubic equation represents the observed values of liquid densities better than the linear equation in the range $-80^{\circ}$ to $+100^{\circ} \mathrm{C}$. the larger value $0.245 \mathrm{~g} / \mathrm{ml}$ is preferred.

The values $P_{c}=32.42$ meters of mercury, $T_{c}=152+273.16^{\circ}$ Kelvin, and $P_{c}=0.245 \mathrm{~g} / \mathrm{ml}$ give

$$
\frac{p_{c} V_{c}}{R T_{c}}=0.270 \text { or } \frac{R T_{c}}{P_{c} V_{c}}=3.70 .
$$

\section{PURITY OF SAMPLES AND MELTING POINT OF PURE BUTADIENE}

The melting curve of a material provides a sensitive method of determining the amount of impurity that is soluble in the liquid phase and insoluble in the solid phase. Such a curve is shown in figure 19 and was obtained as follows:

Starting with the calorimeter containing the sample (in the solid state) at the temperature $A$, measured amounts of electric energy were added and the temperature of the calorimeter observed after thermal equilibrium had been established following each heating. The resultant curve, $A, E, B, C$, gives the temperature of the calorimeter and contents as a function of the energy added. In order to obtain the more useful relation, fraction melted versus temperature, 
the line $A D$ is drawn. This is an extrapolation of the part of the curve representing the energy-temperature relation when the material is all solid. The horizontal distance $E F$ from any observed point to the line $A D$ represents the energy that has been used to melt part of the sample, as $F$ represents the temperature energy condition which would have existed if no material had melted. Accordingly the distance $D B$ represents the total heat of melting. Therefore, if the

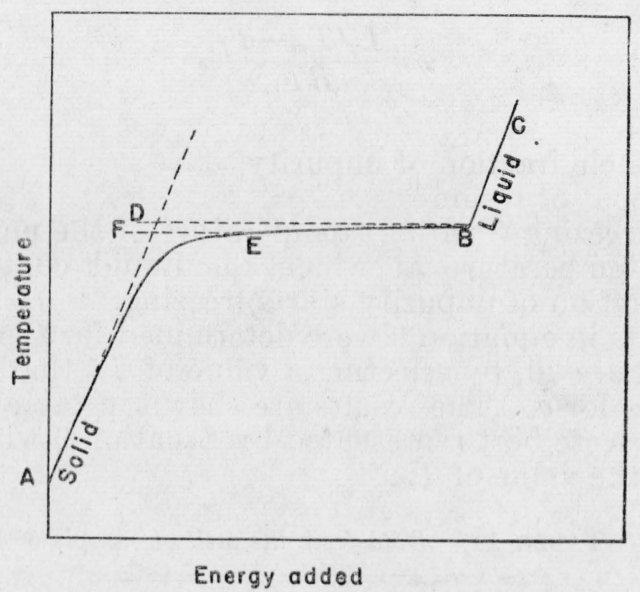

FIGURE 19.-Illustrative meliing curve.

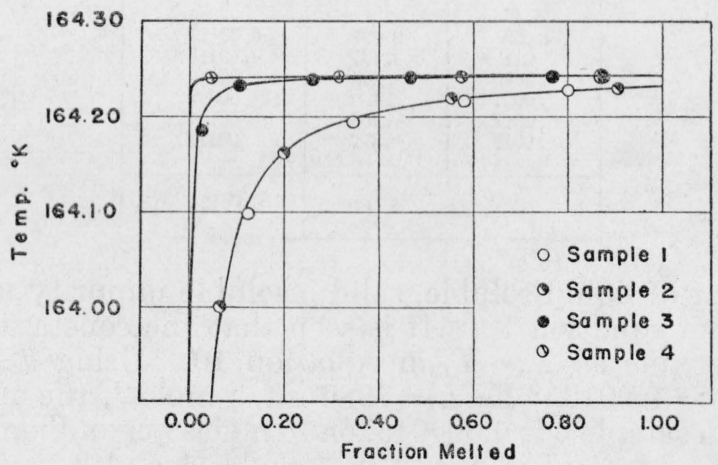

Figure 20.-Melting curves for the four samples of 1,3-butadiene.

heat of fusion is assumed to be constant, the fraction melted at point $E$ is $(E F / D B)$.

Figure 20 shows the melting curves of the four samples, giving the temperature as a function of the fraction melted. The data represented in these curves were used to obtain values for the purity of the samples and for the melting temperature of pure butadiene. If it is assumed that the impurity is soluble in the liquid and insoluble in the solid, then the curves shown in figure 20 will have approximately the form

$$
T_{m}-T=(a / F),
$$


where

$$
\begin{aligned}
T & =\text { temperature at a point on the curve } \\
T_{m} & =\text { melting temperature of pure butadiene } \\
F & =\text { fraction melted } \\
a & =\text { constant }=T_{m}-T(\text { when } F=1) .
\end{aligned}
$$

This equation is derived from the formula relating the depression of the freezing point of a material with the mole fraction of impurity

where

$$
x=\frac{L_{f}\left(T_{m}-T_{f}\right)}{R T_{m}^{2}}
$$

$x=$ the mole fraction of impurity

$L_{f}=$ the heat of fusion

$T_{m}=$ the freezing (melting) temperature of the pure substance

$T_{f}=$ the temperature at which the liquid containing $x$ mole fraction of impurity starts freezing.

The constants in equation 9 were determined for the melting curve of sample 3 , figure 20 , by selecting a value of $T_{m}$ that gave the most constant values for $a$. The results are shown in table 11. The data on this sample were best represented by equation 9 when $164.244^{\circ} \mathrm{K}$ was chosen as the value of $T_{m}$.

\section{TABLE 11.- Data from the melt of sample 3}

\begin{tabular}{|c|c|c|}
\hline$T_{m}-T$ & $F$ & $a=F\left(T_{m}-T\right)$ \\
\hline $0 K$ & & \\
0.059 & 0.027 & 0.00159 \\
.011 & .107 & .00118 \\
.005 & .260 & .00130 \\
.0021 & .466 & .00098 \\
.0017 & .768 & .00131 \\
.0013 & .872 & .00113 \\
\hline & $a$ (mean) & 0.00125 \\
\hline
\end{tabular}

The amount of liquid soluble, solid insoluble impurity may now be computed from equation 10. It is seen that the constant $a$ in equation 9 is the same as $T_{m}-T_{f}$ in equation 10 . Using $T_{m}=164.244^{\circ}$ $\mathrm{K}, T_{m}-T_{f}=a=0.00125^{\circ} \mathrm{K}, L_{f}=7980$ int. $\mathrm{j} \mathrm{mole}{ }^{-1}$, the mole fraction impurity, $x$, in sample 3 is 0.000045 , or 45 moles per million. Calculations of the amounts of impurity in samples 1 and 2 gave 552 moles per million and 516 moles per million, respectively. The treatment of the melting data of samples 1 and 2 yielded a value for $T_{m} 0.006$ degrees Kelvin higher than that obtained from the melt of sample 1. These two samples were so nearly alike that the melting data on both samples were well represented by a single curve.

The curve for sample 4, figure 20 , shows that this was the purest sample obtained. In fact, the melting curve is so flat that only the point at 4.7 percent melted exhibited any measurable depression of the melting point, and even here it amounted to only 0.001 degree Kelvin. The temperature obtained for the other points on the melting curve was $164.242^{\circ} \mathrm{K}$. The liquid soluble, solid insoluble impurity in sample 4 was calculated to be 2 moles per million. 
The difference between the values of the melting point of pure butadiene, 164.244 degree Kelvin, obtained from the data on sample 3, and 164.242 degree Kelvin from the data on sample 4, may have been caused by small errors in the calibrations of the resistance bridges used. Two different Mueller bridges were used for these measurements. This difference of 0.002 degree Kelvin is considerably smaller than the absolute accuracy of temperature measurements, as platinum resistance thermometers, calibrated in the same way, can deviate from each other by as much as 0.01 degree centigrade at $-110^{\circ} \mathrm{C}$. The most probable value of the melting point of pure butadiene, as determined from the data on samples 3 and 4 , is $164.243^{\circ} \pm 0.010^{\circ} \mathrm{K}$ or $-108.917^{\circ} \pm 0.010^{\circ} \mathrm{C}$.

The vapor-pressure measurements at the ice point and above indicated the presence of an impurity that did not appear to affect the melting curves. The vapor pressures of samples 1,2 , and 3 were found to depend somewhat on the fraction condensed, being higher when 95 to 98 percent was condensed than when 75 percent or less was condensed. This indicated the presence of an impurity that was more volatile than butadiene. With sample 3 , which was relatively pure according to the melting curve test, the increase in vapor pressure upon condensing most of the sample amounted to about $6 \mathrm{~mm}$ at $0^{\circ} \mathrm{C}$. The impurity of 45 parts per million, indicated by the melting curve, was not great enough to have caused this increase in vapor pressure. The more elaborate procedure in preparing sample 4 was carried out primarily for the purpose of improving the vaporpressure data. When 96 percent of this sample was condensed at $0^{\circ}$ C the pressure was only $0.3 \mathrm{~mm} \mathrm{Hg}$ higher than when 40 percent was condensed.

In figure 14 the continuous curve represents values calculated for a hypothetical liquid having a vapor pressure of $899 \mathrm{~mm}$ with 0.001 mole fraction of an ideal-gas impurity that is soluble in the hypothetical liquid to the extent of $5.5 \times 10^{-7} \mathrm{moles} / \mathrm{cm}^{3}$ of liquid for a partial pressure of $1 \mathrm{~mm}$. These assumptions, together with the mass of the sample $(0.0275 \mathrm{~g})$, lead to the equation

$$
P=899+\frac{1,000}{3.04 v+45.4},
$$

where $P$ is the total pressure in millimeters of mercury and $v$ is the volume occupied per gram of sample. Although the curve represents the data for sample $3 \mathrm{e}$ very well, the spread in the data permits some variation in the assumed values; moreover, the impurity may not form an ideal solution as assumed.

No specific estimate of the impurity in sample $4 \mathrm{~b}$ can be made because the spread of the data permits a considerable variation in the value assumed for the solubility of the impurity with a corresponding variation in the estimated amount present. It is evident, however, that the amount of more volatile impurity in sample $4 \mathrm{~b}$ was considerably less than that in sample $3 \mathrm{e}$. 


\section{DERIVED PROPERTIES AND FORMULATED TABLES OF THE THERMODYNAMIC PROPERTIES OF I,3-BUTA- DIENE}

\section{ENTROPY AND ENTHALPY OF SOLID AND LIQUID 1,3-BUTADIENE FROM $15^{\circ}$ TO $300^{\circ} \mathrm{K}$}

The tables of specific heat, together with the value of the heat of fusion, were used to calculate the entropy and enthalpy of solid and liquid butadiene. It was first necessary to obtain values of $C_{s a t}$. between $0^{\circ}$ and $15^{\circ} \mathrm{K}$, the latter temperature being the lower limit of the observed data. This was accomplished by using the equation

$$
C_{\text {sat }}=0.7188 D\left(\frac{134}{T}\right) \text {, }
$$

where $C_{\text {sat }}$. is the specific heat in int. $\mathrm{j} \mathrm{g}^{-10} \mathrm{~K}^{-1}$ and $D()$ is the Debye function [11]. This function was selected to represent the data from $15^{\circ}$ to $30^{\circ} \mathrm{K}$, inclusive. The agreement between the observed values of $C_{\text {sat }}$. and those calculated from equation 12 was not entirely satisfactory, but the function was considered adequate for the purpose of extrapolating the specific heat function to $0^{\circ} \mathrm{K}$. The increases in entropy and enthalpy between $0^{\circ}$ and $15^{\circ} \mathrm{K}$ are small compared with the total changes of these quantities between $15^{\circ}$ and $300^{\circ} \mathrm{K}$, so an error in the function used between $0^{\circ}$ and $15^{\circ} \mathrm{K}$ would have little effect on the values obtained at $300^{\circ} \mathrm{K}$.

The calculated values of entropy and enthalpy of the solid and liquid are given at 5-degree intervals in table 12. As different sets of measurements of $C_{\text {sat }}$. were available it was necessary to make a selection in order to use the most reliable values for the calculation of entropy and enthalpy. From $15^{\circ}$ to $55^{\circ} \mathrm{K}$, inclusive, the data on sample 1 were used, as no other data were available in this temperature range. From $60^{\circ} \mathrm{K}$ to the triple point $\left(164.24^{\circ} \mathrm{K}\right.$ ) the data of sample 4 were used because this was the purest sample measured. Above the triple point there was no choice between the data obtained for the different samples so the values of $C_{s a t}$. were simply averaged. Column 2 of table 12 gives these values of $C_{\text {sat }}$. 
TABLE 12.-Entropy and enthalpy of solid and liquid 1, 3-butadiene

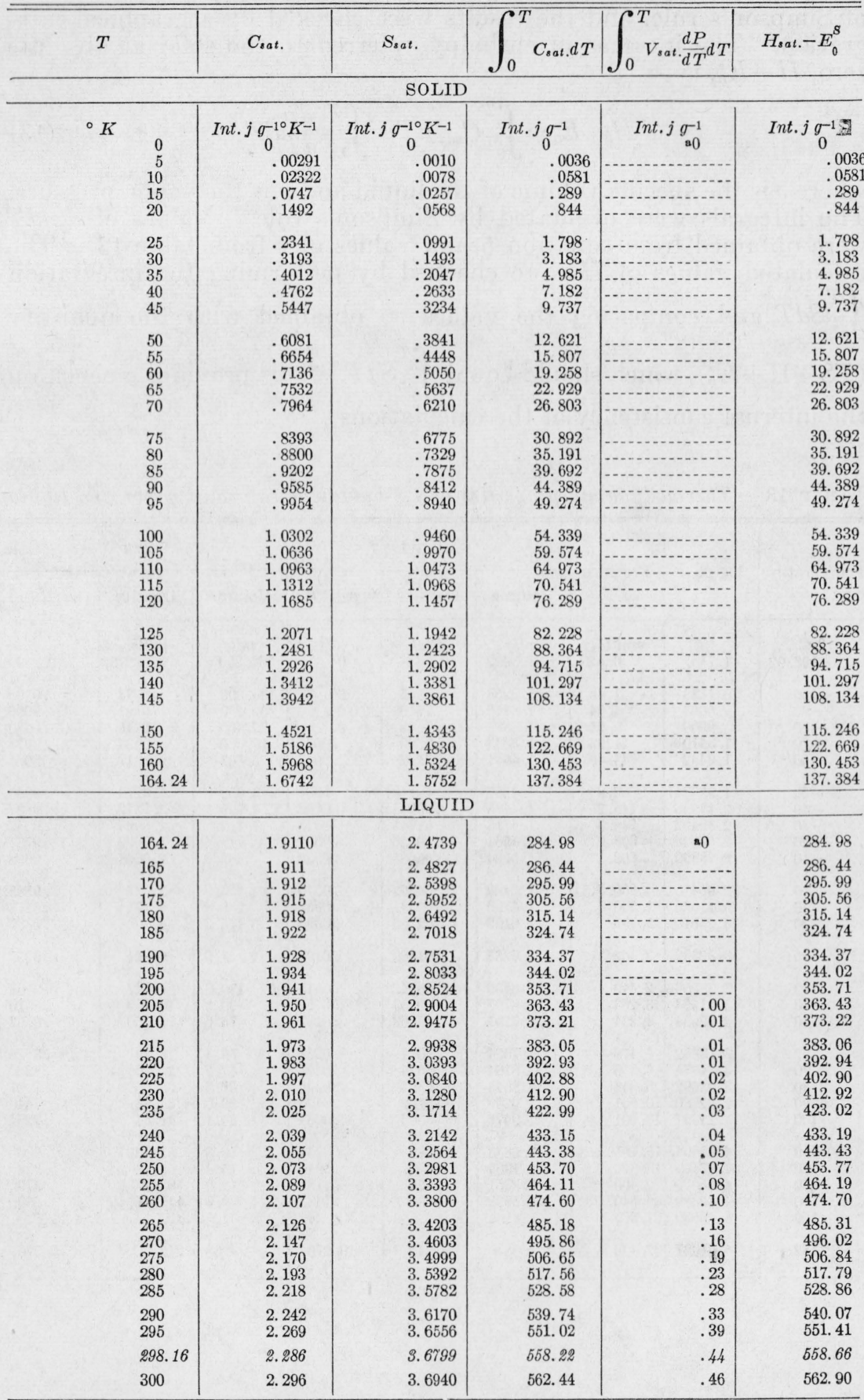

a Column 5 , zero from $0 \circ \mathrm{K}$ to $205^{\circ} \mathrm{K}$.

$649238-45-6$ 
The entropy, $S$, was calculated by integrating $\left(C_{s a t .} / T\right) d T$ by means of Simpson's rule, and the results were checked by a graphical integration. The increase in enthalpy referred to the solid at absolute zero, $H-E_{0}^{:}$, is

$$
H-E_{0}^{s}=\int_{0}^{T} C_{s a l .} d T+\int_{0}^{T} v \frac{d p}{d T} d T,
$$

where $v$ is the specific volume of the liquid and $p$ is the vapor pressure. The integrals were evaluated by Simpson's rule. Values of $d p / d T$ were obtained from equation 5 and values of $v$ from table 13 . The calculated values of $H$ were checked by performing the integration $\int_{0}^{T} S d T$ and comparing the values so obtained with the quantity $\left(T S-\mathrm{H}+E_{0}^{*}\right)$, which should equal $\int_{0}^{T} S d T$. This provides a check on the internal consistency of the calculations.

TABLE 13.- Thermodynamic properties of 1,3-butadiene saturated vapor and liquid

\begin{tabular}{|c|c|c|c|c|c|c|c|c|}
\hline \multirow{2}{*}{ Temperature } & \multirow{2}{*}{$\log p_{m m}$} & \multirow{2}{*}{ Pressure } & \multicolumn{3}{|c|}{ Liquid } & \multicolumn{3}{|c|}{ Vapor } \\
\hline & & & Volume & Density & $p v / R T$ & Volume & Density & $p v / R T$ \\
\hline $\begin{array}{c}{ }^{\circ} C \\
-108.92\end{array}$ & $\overline{1} .7157$ & $\begin{array}{r}m m \mathrm{Hg} \\
0.520\end{array}$ & $\begin{array}{l}m l / g \\
1.3092\end{array}$ & $\begin{array}{l}g / m l \\
0.7638\end{array}$ & 0 & $\begin{array}{c}\mathrm{ml} / \mathrm{g} \\
364,200\end{array}$ & $\begin{array}{l}\text { g/liter } \\
0.00275\end{array}$ & 0.9999 \\
\hline $\begin{array}{l}-100 \\
-90 \\
-80 \\
-70 \\
-60\end{array}$ & $\begin{array}{r}0.1638 \\
.6064 \\
.9960 \\
1.3410 \\
1.6482\end{array}$ & $\begin{array}{r}1.46 \\
4.04 \\
9.91 \\
21.93 \\
44.49\end{array}$ & $\begin{array}{l}1.3253 \\
1.3440 \\
1.3633 \\
1.3833 \\
1.4041\end{array}$ & $\begin{array}{l}.7545 \\
.7440 \\
.7335 \\
.7229 \\
.7122\end{array}$ & $\begin{array}{l}0 \\
0 \\
0 \\
.0001 \\
.0003\end{array}$ & $\begin{array}{r}136,890 \\
52,230 \\
22,450 \\
10,660 \\
5,503\end{array}$ & $\begin{array}{l}.0073 \\
.0191 \\
.0445 \\
.0938 \\
.1817\end{array}$ & $\begin{array}{l}.9998 \\
.9995 \\
.9989 \\
.9978 \\
.9961\end{array}$ \\
\hline $\begin{array}{l}-50 \\
-40 \\
-30 \\
-20 \\
-10\end{array}$ & $\begin{array}{l}1.92334 \\
2.17098 \\
2.39492 \\
2.59836 \\
2.78399\end{array}$ & $\begin{array}{r}83.8 \\
148.2 \\
248.3 \\
396.6 \\
608.1\end{array}$ & $\begin{array}{l}1.4257 \\
1,4483 \\
1.4718 \\
1,4964 \\
1.5224\end{array}$ & $\begin{array}{l}.70140 \\
.69048 \\
.67945 \\
.66826 \\
.65685\end{array}$ & $\begin{array}{l}.0005 \\
.0008 \\
.0013 \\
.0020 \\
.0030\end{array}$ & $\begin{array}{l}3,050 \\
1,795 \\
1,112 \\
719.8 \\
483.8\end{array}$ & $\begin{array}{r}.3279 \\
.5572 \\
.8993 \\
1.3892 \\
2.0668\end{array}$ & $\begin{array}{l}.9935 \\
.9897 \\
.9847 \\
.9781 \\
.9698\end{array}$ \\
\hline $\begin{array}{r}0 \\
10 \\
20\end{array}$ & $\begin{array}{l}\text { 2. } 95410 \\
\text { 3. } 11060 \\
\text { 3. } 25510\end{array}$ & $\begin{array}{l}889.7 \\
1,290 \\
1,799\end{array}$ & $\begin{array}{l}1.5499 \\
1.5790 \\
1.6102\end{array}$ & $\begin{array}{l}.64522 \\
.63331 \\
.62106\end{array}$ & $\begin{array}{l}.0044 \\
.0062 \\
.0086\end{array}$ & $\begin{array}{l}335.9 \\
239.8 \\
175.3\end{array}$ & $\begin{array}{l}2.977 \\
4.171 \\
5.706\end{array}$ & $\begin{array}{l}.9595 \\
.9473 \\
.9330\end{array}$ \\
\hline 25 & 3. 32332 & 2,105 & 1.6265 & .61480 & .0100 & 151.0 & 6.621 & .9250 \\
\hline $\begin{array}{l}30 \\
40 \\
50\end{array}$ & $\begin{array}{l}\text { 3. } 38906 \\
\text { 3. } 51363 \\
\text { 3. } 62984\end{array}$ & $\begin{array}{l}2,449 \\
3,263 \\
4,264\end{array}$ & $\begin{array}{l}1.6436 \\
1.6797 \\
1.7191\end{array}$ & $\begin{array}{l}.60842 \\
.59533 \\
.58169\end{array}$ & $\begin{array}{l}.0115 \\
.0152 \\
.0197\end{array}$ & $\begin{array}{r}130.8 \\
99.3 \\
76.6\end{array}$ & $\begin{array}{r}7.647 \\
10.069 \\
13.060\end{array}$ & $\begin{array}{l}.9164 \\
.8976 \\
.8763\end{array}$ \\
\hline $\begin{array}{r}60 \\
70 \\
80 \\
90 \\
100\end{array}$ & $\begin{array}{l}\text { 3. } 73862 \\
\text { 3. } 84074 \\
\text { 3. } 93692 \\
\text { 4. } 02780 \\
\text { 4. } 11397\end{array}$ & $\begin{array}{r}5,478 \\
6,930 \\
8,648 \\
10,661 \\
13,001\end{array}$ & $\begin{array}{l}1.7624 \\
1.8104 \\
1.8643 \\
1.9259 \\
1.9975\end{array}$ & $\begin{array}{l}.5674 \\
.5524 \\
.5364 \\
.5192 \\
.5006\end{array}$ & $\begin{array}{l}.0251 \\
.0317 \\
.0396 \\
.0490 \\
.0604\end{array}$ & $\begin{array}{l}59.8 \\
47.2 \\
37.5 \\
30.0 \\
24.1\end{array}$ & $\begin{array}{l}16.73 \\
21.20 \\
26.66 \\
33.33 \\
41.54\end{array}$ & $\begin{array}{l}.8526 \\
.8260 \\
.7967 \\
.7640 \\
.7274\end{array}$ \\
\hline $\begin{array}{l}110 \\
120 \\
130 \\
140 \\
150\end{array}$ & $\begin{array}{l}\text { 4. } 19604 \\
\text { 4. } 27459 \\
\text { 4. } 35029 \\
\text { 4. } 42389 \\
\text { 4. } 49639\end{array}$ & $\begin{array}{l}15,705 \\
18,820 \\
22,400 \\
26,540 \\
31,360\end{array}$ & $\begin{array}{l}2.0833 \\
2.1909 \\
2.3351 \\
2.5652\end{array}$ & $\begin{array}{l}.480 \\
.456 \\
.428 \\
.390\end{array}$ & $\begin{array}{l}.0741 \\
.0910 \\
.113 \\
.143\end{array}$ & $\begin{array}{r}19.3 \\
15.4 \\
12.0 \\
9.0\end{array}$ & $\begin{array}{r}51.82 \\
65.08 \\
83.17 \\
111.41\end{array}$ & $\begin{array}{l}.686 \\
.638 \\
.579 \\
.500\end{array}$ \\
\hline 152 & 4. 51087 & 32,420 & 4. 08 & 0.245 & 0.270 & 4. 08 & 245 & 0.270 \\
\hline
\end{tabular}


TABLE 13.-Thermodynamic properties of 1, 3-butadiene saturated vapor_and liquid-Continued

\begin{tabular}{|c|c|c|c|c|c|c|c|c|}
\hline \multirow{2}{*}{ Temperature } & \multicolumn{3}{|c|}{ Enthalpy } & \multicolumn{3}{|c|}{ Entropy } & \multicolumn{2}{|c|}{ Csate } \\
\hline & $\begin{array}{l}H-E_{0}^{*} \\
\text { liquid }\end{array}$ & $\underset{\text { tion }}{\text { Evapora- }}$ & $\begin{array}{c}H-E_{0}^{*} \\
\text { vapor }\end{array}$ & Liquid & $\underset{\text { tion }}{\text { Evapora- }}$ & Vapor & Liquid & Vapor \\
\hline $\begin{array}{l}{ }^{\circ} C \\
-108.92\end{array}$ & $\begin{array}{l}\text { Int. j/g } \\
(284.98)\end{array}$ & $\begin{array}{l}\text { Int. j/g } \\
509.7\end{array}$ & $\begin{array}{l}\text { Int.j/g } \\
794.87\end{array}$ & $\begin{array}{r}\text { Int. } j / g^{\circ} C \\
(2.4739)\end{array}$ & $\begin{array}{r}\text { Int. } j / g^{\circ} C \\
3.1035\end{array}$ & $\begin{array}{r}\text { Int. } j / g^{\circ} C \\
5.5782\end{array}$ & $\begin{array}{r}\text { Int. } j / g^{\circ} C \\
(1.911)\end{array}$ & $\begin{array}{c}\text { Int. } j / g^{\circ} C \\
-2.18\end{array}$ \\
\hline $\begin{array}{l}-100 \\
-90 \\
-80 \\
-70 \\
-60\end{array}$ & $\begin{array}{c}(302.05) \\
321.22 \\
340.50 \\
359.90 \\
379.45\end{array}$ & $\begin{array}{l}501.2 \\
491.8 \\
482.7 \\
473.7 \\
464.9\end{array}$ & $\begin{array}{l}803.30 \\
813.06 \\
823.18 \\
833.63 \\
844.38\end{array}$ & $\begin{array}{c}(2.5749) \\
2.6826 \\
2.7850 \\
2.8829 \\
2.9769\end{array}$ & $\begin{array}{l}2.8944 \\
2.6853 \\
2.4989 \\
2.3318 \\
2.1811\end{array}$ & $\begin{array}{l}\text { 5. } 4695 \\
5.3679 \\
5.2839 \\
5.2147 \\
5.1580\end{array}$ & $\begin{array}{l}(1.914) \\
1.922 \\
1.933 \\
1.947 \\
1.965\end{array}$ & $\begin{array}{l}-1.934 \\
-1.689 \\
-1.471 \\
-1.271 \\
-1.090\end{array}$ \\
\hline $\begin{array}{l}-50 \\
-40 \\
-30 \\
-20 \\
-10\end{array}$ & $\begin{array}{l}399.24 \\
419.29 \\
439.63 \\
460.33 \\
481.40\end{array}$ & $\begin{array}{l}456.2 \\
447.5 \\
438.7 \\
429.7 \\
420.6\end{array}$ & $\begin{array}{l}855.45 \\
866.78 \\
878.33 \\
890.08 \\
901.98\end{array}$ & $\begin{array}{l}3.0675 \\
3.1555 \\
3.2408 \\
3.3241 \\
3.4055\end{array}$ & $\begin{array}{l}2.0443 \\
1.9192 \\
1.8041 \\
1.6975 \\
1.5982\end{array}$ & $\begin{array}{l}5.1118 \\
5.0748 \\
5.0449 \\
5.0216 \\
5.0037\end{array}$ & $\begin{array}{l}1.990 \\
2.019 \\
2.048 \\
2.083 \\
2.122\end{array}$ & $\begin{array}{l}-.926 \\
-.776 \\
-.641 \\
-.518 \\
-.407\end{array}$ \\
\hline $\begin{array}{r}0 \\
10 \\
20\end{array}$ & $\begin{array}{l}502.88 \\
524.80 \\
547.24\end{array}$ & $\begin{array}{l}411.1 \\
401.2 \\
390.9\end{array}$ & $\begin{array}{l}913.99 \\
926.04 \\
938.11\end{array}$ & $\begin{array}{l}3.4854 \\
3.5640 \\
3.6414\end{array}$ & $\begin{array}{l}\text { 1. } 5050 \\
\text { 1. } 4170 \\
\text { 1. } 3333\end{array}$ & $\begin{array}{l}\text { 4. } 9904 \\
\text { 4. } 9810 \\
\text { 4. } 9747\end{array}$ & $\begin{array}{l}2.163 \\
2.207 \\
2.258\end{array}$ & $\begin{array}{r}-.308 \\
-.220 \\
-.141\end{array}$ \\
\hline 25 & 558.66 & 385.5 & 944.12 & 3. 6798 & 1. 2928 & 4. 9726 & 2. 286 & -.108 \\
\hline $\begin{array}{l}30 \\
40 \\
50\end{array}$ & $\begin{array}{l}570.23 \\
593.82 \\
618.01\end{array}$ & $\begin{array}{l}379.9 \\
368.2 \\
355.7\end{array}$ & $\begin{array}{l}950.11 \\
962.01 \\
973.72\end{array}$ & $\begin{array}{l}\text { 3. } 7180 \\
\text { 3. } 7940 \\
\text { 3. } 8694\end{array}$ & $\begin{array}{l}\text { 1. } 2531 \\
\text { 1. } 1757 \\
\text { 1. } 1007\end{array}$ & $\begin{array}{l}\text { 4. } 9711 \\
\text { 4. } 9697 \\
\text { 4. } 9701\end{array}$ & $\begin{array}{l}\text { 2. } 313 \\
2.367 \\
2.427\end{array}$ & $\begin{array}{r}-.073 \\
-.014 \\
+.033\end{array}$ \\
\hline $\begin{array}{r}60 \\
70 \\
80 \\
90 \\
100\end{array}$ & $\begin{array}{l}642.87 \\
668.41 \\
694.67 \\
721.71 \\
749.59\end{array}$ & $\begin{array}{l}342.3 \\
327.8 \\
312.2 \\
295.1 \\
276.2\end{array}$ & $\begin{array}{r}985.17 \\
996.25 \\
1006.84 \\
1016.77 \\
1025.79\end{array}$ & $\begin{array}{l}\text { 3. } 9442 \\
\text { 4. } 0187 \\
\text { 4. } 0930 \\
\text { 4. } 1671 \\
\text { 4. } 2411\end{array}$ & $\begin{array}{r}1.0274 \\
.9554 \\
.8839 \\
.8125 \\
.7402\end{array}$ & $\begin{array}{l}\text { 4. } 9716 \\
\text { 4. } 9741 \\
\text { 4. } 9769 \\
\text { 4. } 9796 \\
\text { 4. } 9813\end{array}$ & $\begin{array}{l}2.489 \\
2.551 \\
2.617 \\
2.688 \\
2.769\end{array}$ & $\begin{array}{r}+.070 \\
+.093 \\
+.099 \\
+.084 \\
.038\end{array}$ \\
\hline $\begin{array}{l}110 \\
120 \\
130 \\
140 \\
150\end{array}$ & $\begin{array}{l}778.5 \\
808.9 \\
841.4 \\
878.8 \\
-\end{array}$ & $\begin{array}{l}255 \\
230 \\
200 \\
158 \\
\end{array}$ & $\begin{array}{l}1033.5 \\
1039.2 \\
1041.6 \\
1036.9\end{array}$ & $\begin{array}{r}\text { 4. } 316 \\
4.392 \\
\text { 4. } 471 \\
\text { 4. } 558 \\
\end{array}$ & $\begin{array}{l}.665 \\
.586 \\
.496 \\
.383 \\
\\
\end{array}$ & $\begin{array}{l}4.981 \\
4.978 \\
4.967 \\
4.941 \\
\end{array}$ & \begin{tabular}{|c|}
2.87 \\
3.02 \\
3.34 \\
\end{tabular} & $\begin{array}{r}-.06 \\
-.24 \\
-.63 \\
-.63 \\
\end{array}$ \\
\hline 152 & $(978)$ & 0 & $(978)$ & (4. 79) & 0 & (4. 79) & & \\
\hline
\end{tabular}

2. THERMODYNAMIC PROPERTIES OF LIQUID AND VAPOR 1,3BUTADIENE FROM $-109^{\circ}$ TO $+150^{\circ} \mathrm{C}$

The experimental data previously described, together with data on the specific heat of the vapor [4], have been used as a basis for the formulation of a consistent set of values for the thermodynamic properties given in tables 13 and 14 . The values given in these tables were calculated from the following empirical equations: vapor pressure (eq 4), vapor density (eq 6), liquid density (eq 8), and

$$
C_{p}^{\circ}=1.3660+0.00445 t-1.88 \times 10^{-8}(t-30)^{3},
$$

where $C_{p}^{\circ}$ is the specific heat of the vapor at zero pressure in international joules per gram degree centigrade, and $t$ is in degrees centigrade. 
TABLE 14.-Thermodynamic properties of 1.3-butadiene superheated vapor

\begin{tabular}{|c|c|c|c|c|c|c|c|c|c|c|}
\hline $\begin{array}{l}\text { Tempera- } \\
\text { ture }\end{array}$ & $C_{p}^{\circ}$ & $C_{p}{ }_{\text {sat. }}-C_{\mathrm{D}}^{\circ}$ & $H^{\circ}-E_{0}^{s}$ & $H^{\circ}-H_{s a t}$ & $S^{\circ}$ & $S^{\circ}-S_{s a t}$ & $H^{\circ}-H_{1} a t m$ & $S^{\circ}-S_{1}$ atm & $(p V / R T)_{1 \text { atm }}$ & $(1 / V)_{1 \mathrm{~atm}}$ \\
\hline $\begin{array}{c}{ }^{\circ} \mathrm{C} \\
-108.92\end{array}$ & $\begin{array}{c}\text { Int. } j / g^{\circ}{ }^{\circ} C \\
0.932\end{array}$ & $\begin{array}{c}\text { Int. } j / g{ }^{\circ} C \\
0.0000\end{array}$ & $\begin{array}{c}\text { Int. } j / g{ }^{\circ} \mathrm{C} \\
794.9\end{array}$ & $\begin{array}{c}\text { Int. } j / g{ }^{\circ} \mathrm{C} \\
0.00\end{array}$ & $\begin{array}{c}\text { Int. } j / g{ }^{\circ} \mathrm{C} \\
\quad 4.4580\end{array}$ & $\begin{array}{c}\text { Int. } j / g{ }^{\circ} C \\
-1.1201\end{array}$ & Int. $j / g$ & Int. $j / g{ }^{\circ} \mathrm{C}$ & & glliter \\
\hline $\begin{array}{l}-100 \\
-90 \\
-80 \\
-70 \\
-60\end{array}$ & $\begin{array}{r}.962 \\
.998 \\
1.035 \\
1.073 \\
1.113\end{array}$ & $\begin{array}{l}.0001 \\
.0003 \\
.0006 \\
.0011 \\
.0023\end{array}$ & $\begin{array}{l}803.31 \\
813.10 \\
823.27 \\
833.81 \\
844.74\end{array}$ & $\begin{array}{l}.01 \\
.04 \\
.09 \\
.18 \\
.36\end{array}$ & $\begin{array}{l}\text { 4. } 5081 \\
\text { 4. } 5632 \\
\text { 4. } 6172 \\
\text { 4. } 6704 \\
\text { 4. } 7229\end{array}$ & $\begin{array}{r}-0.9614 \\
-.8047 \\
-.6667 \\
-.5443 \\
-.4351\end{array}$ & מ. & on. & (1) & - \\
\hline $\begin{array}{l}-50 \\
-40 \\
-30 \\
-20 \\
-10\end{array}$ & $\begin{array}{l}\text { 1. } 153 \\
\text { 1. } 194 \\
\text { 1. } 237 \\
\text { 1. } 279 \\
\text { 1. } 323\end{array}$ & $\begin{array}{l}.0040 \\
.0067 \\
.0106 \\
.0158 \\
.0229\end{array}$ & $\begin{array}{l}856.07 \\
867.81 \\
879.96 \\
892.54 \\
905.55\end{array}$ & $\begin{array}{l}.62 \\
1.03 \\
1.63 \\
2.46 \\
3.57\end{array}$ & $\begin{array}{l}\text { 4. } 7748 \\
\text { 4. } 8263 \\
\text { 4. } 8773 \\
\text { 4. } 9280 \\
\text { 4. } 9784\end{array}$ & $\begin{array}{l}-.3370 \\
-.2483 \\
-.1676 \\
-.0936 \\
-.0253\end{array}$ & (n) & 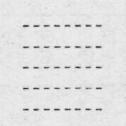 & (n) & p. \\
\hline $\begin{array}{r}0 \\
10 \\
20\end{array}$ & $\begin{array}{l}1.366 \\
1.410 \\
1.455\end{array}$ & $\begin{array}{l}.032 \\
.044 \\
.059\end{array}$ & $\begin{array}{l}919.00 \\
932.88 \\
947.21\end{array}$ & $\begin{array}{l}5.01 \\
6.84 \\
9.10\end{array}$ & $\begin{array}{l}5.0286 \\
5.0785 \\
5.1282\end{array}$ & $\begin{array}{r}+.0382 \\
.0975 \\
.1535\end{array}$ & $\begin{array}{l}\text { 4. } 21 \\
\text { 3. } 95 \\
\text { 3. } 72\end{array}$ & $\begin{array}{r}0.0102 \\
.0093 \\
.0085\end{array}$ & $\begin{array}{r}0.9660 \\
.9696 \\
.9726\end{array}$ & $\begin{array}{l}2.496 \\
2.400 \\
2.311\end{array}$ \\
\hline 25 & 1. 477 & .068 & 954.54 & 10.42 & 5. 1530 & +.1804 & 3. 60 & .0081 & .9740 & 2. 268 \\
\hline $\begin{array}{l}30 \\
40 \\
50\end{array}$ & $\begin{array}{l}1.499 \\
\text { 1. } 544 \\
1.588\end{array}$ & $\begin{array}{l}.078 \\
.101 \\
.130\end{array}$ & $\begin{array}{l}961.98 \\
977.20 \\
992.86\end{array}$ & $\begin{array}{l}11.87 \\
15.19 \\
19.14\end{array}$ & $\begin{array}{l}\text { 5. } 1777 \\
\text { 5. } 2271 \\
\text { 5. } 2764\end{array}$ & $\begin{array}{r}+.2066 \\
.2574 \\
.3063\end{array}$ & $\begin{array}{l}3.48 \\
3.30 \\
3.11\end{array}$ & $\begin{array}{l}.0078 \\
.0071 \\
.0066\end{array}$ & $\begin{array}{l}.9753 \\
.9777 \\
.9798\end{array}$ & $\begin{array}{l}\text { 2. } 228 \\
\text { 2. } 152 \\
\text { 2. } 081\end{array}$ \\
\hline $\begin{array}{r}60 \\
70 \\
80 \\
90 \\
100\end{array}$ & $\begin{array}{l}1.632 \\
1.676 \\
1.720 \\
1.762 \\
1.805\end{array}$ & $\begin{array}{l}.167 \\
.214 \\
.275 \\
.356 \\
.470\end{array}$ & $\begin{array}{l}1008.97 \\
1025.51 \\
1042.49 \\
1059.90 \\
1077.74\end{array}$ & $\begin{array}{l}23.80 \\
29.26 \\
35.65 \\
43.13 \\
51.95\end{array}$ & $\begin{array}{l}\text { 5. } 3254 \\
5.3744 \\
5.4231 \\
\text { 5. } 4718 \\
\text { 5. } 5202\end{array}$ & $\begin{array}{r}+.3538 \\
.4003 \\
.4462 \\
.4922 \\
.5389\end{array}$ & $\begin{array}{l}2.94 \\
2.78 \\
2.64 \\
2.50 \\
2.38\end{array}$ & $\begin{array}{l}.0060 \\
.0056 \\
.0051 \\
.0048 \\
.0044\end{array}$ & $\begin{array}{l}.9817 \\
.9833 \\
.9848 \\
.9861 \\
.9873\end{array}$ & $\begin{array}{l}2.014 \\
1.952 \\
1.894 \\
1.840 \\
1.789\end{array}$ \\
\hline $\begin{array}{l}110 \\
120 \\
130 \\
140 \\
150\end{array}$ & $\begin{array}{l}1.846 \\
1.886 \\
1.926 \\
1.964 \\
2.001\end{array}$ & $\begin{array}{r}.641 \\
.925 \\
1.508 \\
\\
\end{array}$ & $\begin{array}{l}1095.99 \\
1114.65 \\
1133.71 \\
1153.16 \\
1172.99\end{array}$ & $\begin{array}{r}62.51 \\
75.42 \\
92.10 \\
116.29\end{array}$ & $\begin{array}{l}\text { 5. } 5684 \\
\text { 5. } 6166 \\
5.6644 \\
5.7121 \\
5.7594\end{array}$ & $\begin{array}{r}+.5874 \\
.6391 \\
.6973 \\
.7706 \\
\end{array}$ & $\begin{array}{l}2.26 \\
2.15 \\
2.04 \\
1.95 \\
1.85\end{array}$ & $\begin{array}{l}.0041 \\
.0038 \\
.0036 \\
.0033 \\
.0031\end{array}$ & $\begin{array}{l}.9884 \\
.9893 \\
.9902 \\
.9910 \\
.9917\end{array}$ & $\begin{array}{l}1.740 \\
\text { 1. } 694 \\
\text { 1. } 651 \\
\text { 1. } 610 \\
1.571\end{array}$ \\
\hline $\begin{array}{l}200 \\
300 \\
400 \\
500 \\
600\end{array}$ & ( & מ & - & - & מ & - & $\begin{array}{r}\text { a1. } 5 \\
\text { a. } 1.0 \\
\text { a. } 0.7 \\
\text { a. } 5 \\
\text { a. } 3\end{array}$ & $\begin{array}{l}\text { a. } 002 \\
\text { a. } 001 \\
\text { a. } 001 \\
\text { a. } 000 \\
\text { a. } 000\end{array}$ & $\begin{array}{r}\text { a. } 994 \\
\text { a. } 997 \\
\text { a.999 } \\
\text { a. } 999 \\
\text { a. } .000\end{array}$ & $\begin{array}{l}\text { a1. } 400 \\
\text { a. } 152 \\
\text { a. } 980 \\
\text { a. } 852 \\
\text { a. } 755\end{array}$ \\
\hline
\end{tabular}


Equation 14 is in reasonable agreement with results recently reported $[28,29]$ and represents the results reported by Scott and Mellors [4] as follows:

\begin{tabular}{|c|c|c|}
\hline \multirow{2}{*}{$\begin{array}{c}\text { Tempera- } \\
\text { ture }\end{array}$} & \multicolumn{2}{|c|}{ Specific heat, $C_{p}^{\circ}$ int. $\mathrm{j} / \mathrm{g}{ }^{\circ} \mathrm{C}$} \\
\cline { 2 - 3 } & Reported & $\begin{array}{c}\text { Calculated, } \\
\text { eq } 14\end{array}$ \\
\hline$\circ C$ & & \\
-35 & 1.217 & 1.215 \\
0 & 1.366 & 1.366 \\
40 & 1.549 & 1.544 \\
80 & 1.721 & 1.720 \\
\hline
\end{tabular}

Values of the tabulated quantities $H^{\circ}-E_{0}^{s}$ and $S^{\circ}$ for the vapor were calculated from equations obtained by substituting the definitions $d H=C_{p} d T$ and $d S=\left(C_{p} / T\right) d T$ in equation 14 and performing the integration. These equations are $(t-30)^{4}$

$$
H^{\circ}-E_{0}^{s}=919.00+1.3660 t+0.002225 t^{2}-0.47 \times 10^{-8}
$$

and

$$
\begin{aligned}
S^{\circ}=0.93615+1.55252 & \log T-0.0007335 T \\
& +8.549(10)^{-6} T^{2}-6.2667(10)^{-9} T^{3},
\end{aligned}
$$

where $E_{0}^{s}$ is the internal energy of the solid at absolute zero, $H^{\circ}$ in international joules per gram, and $S^{\circ}$ in international joules per gram degree centigrade represent the ideal gas state at 1-atm pressure, $t$ is in degrees centigrade, and $T=t+273.16$. The constants of integration were chosen to make the calculated values for the liquid agree as closely as possible with the values in table 12 .

The tabulated values for the specific heat of the liquid were calculated from the specific heat of the vapor with the aid of the following exact thermodynamic relations:

$$
\begin{gathered}
\left(C_{s}\right)_{s}=\left(C_{s}\right)_{l}+T \frac{d(L / T)}{d T} \\
\left(C_{p}\right)_{s a t}=\left(C_{s}\right)_{s}+T\left(\frac{\partial V}{\partial T}\right)_{p}\left(\frac{d p}{d T}\right)_{s a t} . \\
C_{v}=C_{p}-T\left[\left(\frac{\partial V}{\partial T}\right)_{p}\left(\frac{\partial p}{\partial T}\right)_{V}\right] \\
C_{v}^{\circ}=C_{v}-\int_{\infty}^{v} T\left(\frac{\partial^{2} p}{\partial T^{2}}\right)_{V} d V \\
C_{p}^{\circ}=C_{v}^{\circ}+R
\end{gathered}
$$

where $\left(C_{s}\right)_{g}$ and $\left(C_{s}\right)_{l}$ are the specific heats of saturated vapor and liquid, respectively, $C_{p}$ and $C_{v}$ are the specific heats of the vapor at constant pressure and volume, respectively, and $C_{p}^{\circ}$ and $C_{v}^{\circ}$ are the corresponding values at zero pressure. The procedure just described may appear to be reversed from the normal, as the experimental values of specific heat of the liquid are the more accurate and had already been tabulated in table 12. These values did not extend above 
$20^{\circ} \mathrm{C}$, however, and at least a tentative formulation for the vapor would have been necessary to obtain values for the liquid above that temperature. Moreover, formulation for the liquid is necessarily limited to temperatures below the critical, whereas the limitations for the procedure used depend only upon the accuracy with which the chosen formula can be extrapolated.

The tabulated valus of $L$ and $L / T$ were calculated from the Clapeyron equation written in the dimensionless form

$$
\frac{L}{R T}=\left[\left(\frac{p V}{R T}\right)_{g}-\left(\frac{p V}{R T}\right)\right]_{l}\left(T \frac{d \ln p}{d T}\right),
$$

values of $p V / R T$ from table 13 being used. The quantity $T(d \ln p) / d T$ was calculated from equation 5 . Values of the quantity $d(L / T) / d T$ were calculated from the values of $L / T$ by the Rutledge method. The various other derivatives were obtained through differentiation of equation 8 .

The tabulated values of enthalpy and entropy were calculated from the equations

$$
\begin{gathered}
\frac{H^{0}-H}{R T}=\frac{14.1747\left(T_{c} / T\right)^{2} 10^{-0.045(T c / T)^{2}}+68.4\left(1-10^{\left.-0.045\left(T_{c} / T\right)^{2}\right)}-148\right.}{V}- \\
\frac{S^{0}-S}{R}=\ln \frac{1.5171 T}{V}+ \\
\frac{14.1747\left(T_{c} / T\right)^{2} 10^{-0.045(T c / T)^{2}}-68.4\left(1-10^{-0.045(T c / T)^{2}}\right)+1.48}{2 V^{2}+7} \\
V
\end{gathered}
$$

where $V$ is in milliliters per gram, $H^{\circ}$ and $S^{\circ}$ are given by equations 14 and 15 , and $R$ is 0.15369 int. $\mathrm{j} / \mathrm{g}^{\circ} \mathrm{C}$. Equations 23 and 24 were derived from equation 8 . The values in table 13 are in excellent agreement with values interpolated from table 12. Except for the values shown in parentheses in table 13 , which were obtained from table 12 , the largest differences are 0.05 int. $\mathrm{j} / \mathrm{g}$ in the enthalpy at $-70^{\circ} \mathrm{C}, 0.0002$ int. $\mathrm{j} / \mathrm{g}^{\circ} \mathrm{C}$ in the entropy at several temperatures, and 0.002 int. $\mathrm{j} / \mathrm{g}^{\circ} \mathrm{C}$ in the specific heat of the saturated liquid.

In order to retain accuracy on differences, most of the items in table 13 and some in table 14 are given to more places than the accuracy of the individual values would warrant. Although in some cases the values in the tables may be in error by a somewhat greater amount, the following are considered reasonable tolerances:

1. Vapor pressures: $0.1 \mathrm{~mm}$ or slightly better at low temperatures, 0.05 to 0.1 percent for $-20^{\circ}$ to $+110^{\circ} \mathrm{C}$, and about 1 percent at the critical temperature.

2 Liquid densities: $0.00005 \mathrm{~g} / \mathrm{ml}$ near zero,

$$
\begin{aligned}
& 0.0001 \text { between }-30 \text { and }+30^{\circ} \mathrm{C} \text {, } \\
& 0.001 \text { below } 100^{\circ} \mathrm{C} \text {. }
\end{aligned}
$$

3. Vapor densities: 0.1 or 0.2 percent,

1 or 2 percent near the critical temperature. 
4. Enthalpy of evaporation: Same as vapor densities.

5. Specific heats: Liquid below $20^{\circ} \mathrm{C}$ about 0.1 percent, the uncertainty increasing at higher temperatures, becoming very large near the critical temperature: vapor between $-35^{\circ}$ and $+80^{\circ} \mathrm{C}$ about 0.5 percent, the uncertainty increasing greatly as the critical temperature is approached.

6. Enthalpy and entropy differences: Same as for specific heats.

The assistance of L. A. Matheson, of the Research Laboratory, Dow Chemical Co., in providing pure 1,3-butadiene for this investigation is gratefully acknowledged. The authors express their thanks to Patricia Husbands, who performed a large part of the calculations involved in determining the constants of the equations in this formulation and in preparing tables 13 and 14.

\section{REFERENCES}

[1] R. B. Scott, R. D. Rands, Jr., F. G. Brickwedde, Report to the Office of the Rubber Director (July 23, 1943).

[2] C. H. Meyers, R. B. Scott, F. G. Brickwedde, R. D. Rands, Jr., Report to the Office of the Rubber Director (June 30,1943).

[3] L. A. Wood and C. F. Higgins, NBS Letter Circular LC710 (1942).

[4] Russell B. Scott and Jane W. Mellors, J. Research NBS 34, 243 (1945) RP1640.

[5] Martin Shepherd, BS J. Research 12, 185 (1934) RP643.

[6] J. C. Southard and F. G. Brickwedde, J. Am. Chem. Soc. 55, 4378 (1933).

[7] J. C. Southard and R. T. Milner, J. Am. Chem. Soc. 55, 4384 (1933).

[8] Harold J. Hoge and F. G. Brickwedde, J. Research NBS 22, 351 (1939) RP1188; 22, 217 (1942) RP1454.

[9] N. S. Osborne, BS J. Research 4, 609 (1930) RP168.

[10] N. S. Osborne, H. F. Stimson, T. S. Sligh, and C. S. Cragoe, BS Sci. Pap. 20, 65 (1925) S501.

[11] J. A. Beattie, J. Math. Phys. 6, 1 (1926).

[12] N. S. Osborne, H. F. Stimson, and D. C. Ginnings, NBS J. Research 23, 197 (1939) RP1228.

[13] C. H. Meyers, J. Am. Chem. Soc. 45, 2135 (1923).

[14] C. H. Meyers and R. S. Jessup, BS J. Research 6, 1061 (1931) RP324.

[15] G. K. Burgess, BS J. Research 1, 635 (1928) RP22.

[16] Wm. E. Vaughan, J. Am. Chem. Soc. 54, 3863 (1932).

[17] G. B. Heisig, J. Am. Chem. Soc. 55, 2304 (1933).

[18] G. Moor and E. K. Kanep, Trans. Experimental Research Lab., Chemgas [III] Leningrad (1936).

[19] A. B. Lamb and E. E. Roper, J. Am. Chem. Soc. 62, 806 (1940).

[20] C. S. Cragoe, NBS Letter Circular LC 736 (1943).

[21] C. Prevost, Comp. rend. 186, 1209 (1928).

[22] I. G. Farbenindustrie Ludwigshafen (1929) Landolt-Bornstein Physical Chemical Tables, 5th edition, 2d supplement, part I, page 207.

[23] Some physical constants of seven four-carbon-atom hydrocarbons and neopentane, Petroleum Refining Laboratory, Pennsylvania State College, Thesis (1941).

[24] M. R. Dean and T. W. Legatski, Ind. Eng. Chem. 36, 7 (1944).

[25] R. F. Robey, H. K. Wiese, and C. E. Morrell, Ind. Eng. Chem. 36, 3 (1944).

[26] The storage of 1,3-butadiene, Research Bul. 7.381-B, Mellon Inst. Ind. Research.

[27] C. H. Meyers, BS J. Research 11, 691 (1933) RP616.

[28] J. G. Aston, G. W. Moessen, H. C. Hardy, and G. J. Szasz, J. Chem. Phys. 12, 458 (1944).

[29] D. H. Templeton, D. D. Davies, and W. A. Felsing, J. Am. Chem. Soc. 66, 2033 (1944).

Washington, April 30, 1945. 